\title{
A First-in-Class Small-Molecule that Acts as a Dual Inhibitor of HDAC and PDE5 and that Rescues Hippocampal Synaptic Impairment in Alzheimer's Disease Mice
}

\author{
Mar Cuadrado-Tejedor 1,2,7, Carolina Garcia-Barroso',7, Juan A Sánchez-Arias ${ }^{3}$, Obdulia Rabal ${ }^{3}$, \\ Marta Pérez-González', Sara Mederos ${ }^{4}$, Ana Ugarte ${ }^{3}$, Rafael Franco ${ }^{1,5}$, Victor Segura ${ }^{6}$, Gertrudis Perea ${ }^{4}$, \\ Julen Oyarzabal ${ }^{*, 3,8}$ and Ana Garcia-Osta ${ }^{*, 1,8}$ \\ 'Neurobiology of Alzheimer's Disease, Neurosciences Division, Center for Applied Medical Research (CIMA), University of Navarra, Pamplona, \\ Spain; ${ }^{2}$ Anatomy Department, School of Medicine, University of Navarra, Pamplona, Spain; ${ }^{3}$ Small Molecule Discovery Platform, Molecular \\ Therapeutics Program, Center for Applied Medical Research (CIMA), University of Navarra, Pamplona, Spain; ${ }^{4}$ Cajal Institute, CSIC, Madrid, Spain; \\ ${ }^{5}$ Department of Biochemistry and Molecular Biology, Faculty of Biology, University of Barcelona, Barcelona, Spain; 'Bioinformatics Unit, Center for \\ Applied Medical Research (CIMA), University of Navarra, Pamplona, Spain
}

The targeting of two independent but synergistic enzymatic activities, histone deacetylases (HDACs, class I and HDAC6) and phosphodiesterase 5 (PDE5), has recently been validated as a potentially novel therapeutic approach for Alzheimer's disease (AD). Here we report the discovery of a new first-in-class small-molecule (CM-4I4) that acts as a dual inhibitor of PDE5 and HDACs. We have used this compound as a chemical probe to validate this systems therapeutics strategy, where an increase in the activation of cAMP/cGMPresponsive element-binding protein (CREB) induced by PDE5 inhibition, combined with moderate HDAC class I inhibition, leads to efficient histone acetylation. This molecule rescued the impaired long-term potentiation evident in hippocampal slices from APP/PSI mice. Chronic treatment of Tg2576 mice with CM-4I 4 diminished brain A $\beta$ and tau phosphorylation (pTau) levels, increased the inactive form of GSK3 $\beta$, reverted the decrease in dendritic spine density on hippocampal neurons, and reversed their cognitive deficits, at least in part by inducing the expression of genes related to synaptic transmission. Thus, CM-4I 4 may serve as the starting point to discover balanced dual inhibitors with an optimal efficacy and safety profile for clinical testing on AD patients.

Neuropsychopharmacology (2017) 42, 524-539; doi:I0.1038/npp.2016.163; published online 21 September 2016

\section{INTRODUCTION}

The discouraging results of therapies for Alzheimer's disease (AD) in clinical trials, $99.6 \%$ failure from 2002 to 2012 (Cummings et al, 2014), highlights the urgent need for new approaches to achieve effective therapy. Traditional approaches are generally directed toward a single pathway, in the case of $\mathrm{AD}$ mostly focused on lowering $\beta$-amyloid levels. However, as for others complex diseases, it is becoming clear that $\mathrm{AD}$ therapies should focus on the simultaneous modulation of several targets implicated in the disease (Zheng et al, 2015). In this sense, we recently validated the efficacy of a new systems therapeutics approach focused on the concomitant inhibition of histone

\footnotetext{
*Correspondence: Dr I Oyarzabal or Dr A Garcia-Osta, CIMA, University of Navarra, Pio XII, 55, Pamplona 31008, Spain, Tel: +34 9481947 00, Fax: +34 9481947 15, E-mail: julenoyarzabal@unav.es or agosta@unav.es

${ }^{7}$ The first two authors contributed equally to this work.

${ }^{8}$ The last two authors contributed equally to this work.

Received 7 March 2016; revised 27 July 2016; accepted 30 July 20 I6; accepted article preview online 23 August 2016
}

deacetylases (HDACs) and phosphodiesterase 5 (PDE5) in $\mathrm{AD}$ mice (Cuadrado-Tejedor et al, 2015).

PDE5 is upregulated in AD brains, often in conjunction with a decrease in cGMP in the cerebrospinal fluid (CSF) of $\mathrm{AD}$ patients (Ugarte et al, 2015), drawing attention to the possible therapeutic potential of PDE5 inhibitors in $\mathrm{AD}$ (Cuadrado-Tejedor et al, 2011a; Garcia-Barroso et al, 2013; Puzzo et al, 2009). It has been proposed that the activation of the cGMP/cAMP-responsive element-binding protein (CREB) pathway, which is crucial for memory formation, may contribute to the amelioration of $\mathrm{AD}$ symptoms observed with PDE5 inhibitors in animal models (Garcia-Osta et al, 2012; Puzzo et al, 2005). Similarly, histone deacetylase inhibitors (HDACis) have emerged as promising new therapeutic agents for $\mathrm{AD}$ (Benito et al, 2015; Kilgore et al, 2010; Ricobaraza et al, 2009). The 18 known HDAC isoforms are divided into four classes (I-IV) and it is not fully clear which HDAC isoforms might be involved in the therapeutic effects of pan-HDACis observed in $\mathrm{AD}$ models. Class I HDAC and HDAC6 have been implicated in $\mathrm{AD}$ memory-related dysfunction (Ding et al, 2008; Guan et al, 2009), and among class I, HDAC2 and HDAC3 are critical to control multiple memory-related genes. Indeed, 
these enzymes have been described as negative regulators of memory consolidation (Guan et al, 2009; McQuown et al, 2011). In contrast, HDAC6 regulates microtubule function and stability via tubulin acetylation (Guan et al, 2009; Hubbert et al, 2002), and dampening HDAC6 activity promotes tau and $\mathrm{A} \beta$ clearance (Cook et al, 2012; Sung et al, 2012; Zhang et al, 2014). Notably, HDAC2 and HDAC6 are overexpressed in the cortex and hippocampus of $\mathrm{AD}$ patients, although the cause and effect of this upregulation remains unknown (Ding et al, 2008; Graff et al, 2012).

Most of the HDACis that are effective in $\mathrm{AD}$ models have little isoform selectivity that has been associated with unfavorable side effects. Thus, it is believed that isozymeselective HDACis may be more effective and less toxic (Langley et al, 2005). Nevertheless, not every isoformselective HDACi has a good safety profile and, in fact, the potency of HDACis that target each class I isoform independently (HDAC1, HDAC2, and HDAC3) is associated with cytotoxicity, whereas the inhibition of HDAC6 does not affect cell survival (Robers et al, 2015). In addition, toxicity not only depends on the inhibition of HDAC class I isoforms but it is also influenced by the compound's kinetic properties that are crucial to maintain cell viability (Lauffer et al, 2013). It has been hypothesized that a short exposure of neurons to HDACis may be sufficient to provide neuroprotection while avoiding toxicity (Langley et al, 2008). In fact, HDACi with fast dissociation kinetics rates (such as hydroxamates) limit the overexpression of genes involved in cell cycle regulation and thus cytotoxicity (Lauffer et al, 2013). Moreover, in the case of memory function, an initial, rapid, and transient induction of early-immediate genes (IEGs) would be sufficient to induce long-lasting changes in memory consolidation (Sheng and Greenberg, 1990; Tzingounis and Nicoll, 2006).

Based on previous knowledge, we defined the profile of a target compound that would serve as an appropriate chemical probe that could be used to test the systems therapeutics approach for $\mathrm{AD}$ treatment recently discovered (Cuadrado-Tejedor et al, 2015). As such, we searched for a brain penetrant dual inhibitor with an adequate balance in terms of inhibitory activity (a moderate class I HDACi with potent inhibition of HDAC6 and PDE5) that is capable of producing an optimal functional response (activation of memory-related genes through increasing lysine acetylation and/or CREB phosphorylation) with minimal impact on cell survival, and with a short residence time and reduced half-life. This strategy led to the identification of a chemical probe with the appropriate profile, first-in-class smallmolecule (CM-414), that has therapeutic effects when administered chronically to $\mathrm{AD}$ mice in the absence of associated safety issues. Thus, we believe that this compound represents an optimal starting point to launch an $\mathrm{AD}$ drug discovery program based on this validated systems therapeutics approach.

\section{MATERIALS AND METHODS}

\section{Structure-Based Design of CM-414}

CM-414 was superposed to the conformation of sildenafil in the cocrystal structure of the sildenafil-PDE5 complex (Protein Data Bank, PDB, entry 1TBF) with the MOE program (Chemical Computing Group, Molecular Operating Environment, MOE 2012.10 (2012), Montreal, Quebec, Canada; http://www.chemcomp.com/). Then, the overlaid conformation of CM-414 was translated into the sildenafilPDE5 crystal (PDB entry 1TBF) in order to analyze the key interactions between CM-414 and the phosphodiesterase, specially the orientation of the hydroxamic moiety.

For HDAC2, CM-414 was superposed to the conformation of vorinostat in the cocrystal structure of vorinostat-HDAC2 complex (PDB entry 4LXZ) with the MOE program and, again, the superposed conformation of CM-414 was translated into the $4 \mathrm{LXZ}$ crystal. In the case of HDAC2, the hydroxamic moiety interacts with the zinc ion and polar residues and the pyrazolopyrimidinone core positions at the entrance of the binding pocket, oriented toward solvent, where interaction with Asp104 is also proposed. For PDE5, an opposite orientation is predicted. Here, the hydroxamic group orients toward solvent, whereas the central scaffold interacts with the same key residues as for sildenafil: Gln817 and Phe820 ( $\pi-\pi$ stacking); in addition, through two different water molecules, pyrazolopyrimidinone might also interact with Gln775, Tyr612, and Asp764.

\section{Synthesis of Novel Compound: CM-414 (and Their Corresponding Isomers)}

See Supplementary Materials and Methods.

\section{HDAC and PDE Enzyme Activity Assays}

HDAC enzyme activities were measured with a specific fluorescence-labeled substrate (BPS Biosciences, Cat. no. 50037) after its deacetylation by HDACs. The fluorogenic substrate, containing an acetylated lysine side chain, can be deacetylated and then sensitized to subsequent treatment with the lysine developer that produces a fluorophore that can be measured with a fluorescence plate reader. Human HDAC1 (GenBank Accession No. NM_004964), full length, with C-terminal His-tag and C-terminal Flag-tag, was obtained from BPS Biosciences (Cat. no. 50051). Human HDAC2 (GenBank Accession No. NM_001527), full length, with C-terminal His-tag was obtained from BPS Biosciences (Cat. no. 50002). Human HDAC3 (GenBank Accession No. NM_003883), full length, with C-terminal His-tag and human NCOR2, N-terminal GST-tag, was obtained from BPS Biosciences (Cat. no. 50003). Human HDAC6 (GenBank Accession No. BC069243), full length with N-terminal GST tag, was obtained from BPS Biosciences (Cat. no. 50006). Then, $5 \mu \mathrm{l}$ of vehicle or tested compound $10 \times$ concentrated prepared in assay buffer (BPS Biosciences, Cat no. 50031) were added in black 96-well plates (final volume of $100 \mu \mathrm{l}$ ). The final percentage of DMSO was $1 \%$. Next, $5 \mu \mathrm{l}$ of HDAC1 $(4 \mu \mathrm{g} / \mathrm{ml})$ or HDAC2 $(15 \mu \mathrm{g} / \mathrm{ml})$ or HDAC3 $(10 \mu \mathrm{g} / \mathrm{ml})$ or HDAC6 $(36 \mu \mathrm{g} / \mathrm{ml})$ enzyme in assay buffer was added (final HDAC1, HDAC2, HDAC3, and HDAC6 concentration of $0.4,1.5,0.1$, and $3.6 \mu \mathrm{g} / \mathrm{ml}$, respectively) and the reaction was started by the addition of $40 \mu \mathrm{l}$ of reaction mixture containing $0.125 \mathrm{mg} / \mathrm{ml} \mathrm{BSA}$ (final concentration of $0.1 \mathrm{mg} / \mathrm{ml}$ ) and $12.5 \mu \mathrm{M}$ of fluorogenic HDAC substrate (final concentration of $10 \mu \mathrm{M}$ ). The reaction was incubated for $30 \mathrm{~min}$ at $37^{\circ} \mathrm{C}$. After incubation, the reaction was 
stopped with $50 \mu \mathrm{l}$ of lysine assay developer (BPS Biosciences, Cat. no. 50030). After incubation for $20 \mathrm{~min}$ at room temperature, the fluorescence of each well was measured at $355 \mathrm{~nm}$ excitation and $460 \mathrm{~nm}$ emission in a Mithras plate reader (Berthold). Positive control was obtained in the presence of the vehicle of the compounds. Negative control was obtained in the absence of HDAC enzyme activity. A best fit curve was fitted using GraphPad Prism 5 to derive the half-maximal inhibitory concentration $\left(\mathrm{IC}_{50}\right)$ from this curve.

PDE5A enzyme activity was measured with the HTRF cGMP assay kit from CisBio (CisBio, Cat. no. 62GM2PEB) that which determines the amount of cGMP present in the reaction. Human PDE5A1 (GenBank Accession No. NM_001083) or human PDE9A isoform b (GenBank Accession No. NM_001083), full length, with N-terminal GST tag, was obtained from BPS Biosciences (Cat. no. 60050 or 60090$)$. Then, $2.5 \mu \mathrm{l}$ of vehicle or tested compound $4 \times$ concentrated prepared in assay buffer $(50 \mathrm{mM}$ Tris- $\mathrm{HCl}$, $6 \mathrm{mM} \mathrm{MgCl}_{2}, \mathrm{pH} 7.4$ ) were added in 384-well plates (final volume of $20 \mu \mathrm{l}$ ). The final percentage of DMSO was $0.5 \%$; $2.5 \mu \mathrm{l}$ of PDE5A $(7 \mu \mathrm{g} / \mathrm{ml})$ or of PDE9A $(0.2 \mu \mathrm{g} / \mathrm{ml})$ enzyme in assay buffer was added (final PDE5A concentration $1.75 \mu \mathrm{g} / \mathrm{ml}$ or final PDE9A concentration $0.05 \mu \mathrm{g} / \mathrm{ml}$ ) and the reaction was started by the addition of $5 \mu \mathrm{l}$ of substrate cGMP $(4 \times$ concentrated $)$ to a final concentration of $100 \mathrm{nM}$ cGMP. The reaction was incubated for $30 \mathrm{~min}$ at $37^{\circ} \mathrm{C}$. After incubation, the reaction was stopped with $5 \mu$ of cGMP-D2 (cGMP labeled with the dye D2) and $5 \mu$ l of MAb anti-cGMP labeled with cryptate (cGMP-cryptate). After incubation during $1 \mathrm{~h}$ at room temperature, the fluorescence of each well was measured at $665 \mathrm{~nm}$ excitation and $620 \mathrm{~nm}$ emission in an Envision plate reader (PerkinElmer) and the results were expressed as the $665 \mathrm{~nm} / 620 \mathrm{~nm}$ ratio. Positive control was obtained in the presence of the vehicle of the compounds. Negative control was obtained in the absence of cGMP and labeled cGMP-D2 cyclic nucleotide. A best fit curve was fitted using GraphPad Prism 5 to derive $\mathrm{IC}_{50}$ from this curve.

\section{MMP-3 and MMP-10 Enzyme Activity Assays}

See Supplementary Materials and Methods.

\section{HDAC4, HDAC5, HDAC7, HDAC8, HDAC9, HDAC10, and HDAC11 Enzyme Activity Assays}

These assays were carried out at Eurofins (www.eurofins. com).

\section{Primary Neuronal Cultures and Treatments}

Primary neuronal cultures were obtained from the hippocampus and cortex of embryonic day 16 (E16) wild-type (WT) or Tg2576 mice and used at 15 or 21 days in vitro (DIV) (Ricobaraza et al, 2009). Tg2576 mice express the human 695-aa isoform of amyloid precursor protein (hAPP) containing the Swedish double mutation that favors $\mathrm{A} \beta$ production. To analyze the functional activity of CM-414 in vitro cultures (WT or Tg2576 at DIV 15) were treated with CM-414 at different concentrations (10$100 \mathrm{nM}$ ) during $30 \mathrm{~min}$ or $2 \mathrm{~h}$. For western blot analysis, hippocampal neurons were collected after the different treatments in a lysis buffer containing Tris- $\mathrm{HCl} 10 \mathrm{mM}$, $\mathrm{NaF} 1 \mathrm{mM}, \mathrm{NaVO}_{4} 0.1 \mathrm{mM}$, sodium dodecyl sulfate (SDS) $2 \%$, and protease inhibitors.

The effects of CM-414 on amyloid and tau pathology were analyzed in primary neuronal cultures (DIV 21) derived from Tg2576 mouse embryos. For hAPP processing and tau phosphorylation (pTau), neurons were treated for 2 days at $100 \mathrm{nM}$ and collected at day 3, $24 \mathrm{~h}$ after the last treatment. The effect of CM-414 on hAPP processing by the amyloidogenic pathway was analyzed by western blot analysis measuring the 99-amino-acid-long APP-carboxyterminal fragments (APP-CTFs) designated C99, the precursor of $\mathrm{A} \beta_{42}$ (Garcia-Osta and Cuadrado-Tejedor, 2016). We next analyzed the effect of CM-414 on levels of phosphorylated tau in the same samples using a phosphospecific antibody (AT8) that recognizes hyperphosphorylated epitopes on Ser202/Thr205.

\section{Acetyl-Histone H3 Lysine 9 (H3K9ac) Cellular Detection Assay (AlphaLisa Technology)}

Briefly, 2000 cells (human neuroblastoma SH-SY5Y cell line) were plated in a poly-D-lysine-treated 384-well plate. Cells were incubated with different concentrations of CM-414 during $2 \mathrm{~h}$. After incubation, medium was removed and cells were lysed, histones were extracted, and histones carrying the acetylation mark were detected following the manufacturer's instructions (PerkinElmer; Cat. no. AL714 A/C kit assay). Signal of acetylation mark was obtained after $18 \mathrm{~h}$ of dark incubation at room temperature and was normalized by the unmodified histone signal and calculated as folds over basal levels, considered as those obtained in the absence of assayed compounds. Statistical significance of differences values was calculated by the unpaired Student's $t$-test. The differences were considered statistically significant when $p<0.05$.

\section{Slice Recordings}

Brain slices were obtained from APP/PS1 mice, positive and WT littermates mice. APP/PS1 mice expressing a human APPswe and a human presinilin 1 (PS1dE9) have been previously described (Borchelt et al, 1996). APP/PS1 transgenic mice developed $\mathrm{A} \beta$ plaques in the cerebral cortex at the age of 3 months and began to have deficits in learning and memory at the age of 6 months. For slice recordings, animals at 6-9 months were used. After mice were anesthetized and decapitated, brains were rapidly removed, placed in ice-cold modified cutting extracellular solution, and sectioned in slices $(400 \mu \mathrm{m})$. Slices were incubated during $>1 \mathrm{~h}$ at room temperature $\left(22-24^{\circ} \mathrm{C}\right)$ in standard extracellular solution containing (in $\mathrm{mM}$ ): $\mathrm{NaCl} 124, \mathrm{KCl}$ 2.69, $\mathrm{KH}_{2} \mathrm{PO}_{4} 1.25, \mathrm{MgSO}_{4} 2, \mathrm{NaHCO}_{3} 26, \mathrm{CaCl}_{2}$ 2, and glucose 10, and was gassed with $95 \% \quad \mathrm{O}_{2} / 5 \% \quad \mathrm{CO}_{2}$ $(\mathrm{pH}=7.35)$. Cutting solution contained (in $\mathrm{mM}): \mathrm{N}$ methyl-D-glucamin 93, KCl 2.5, $\mathrm{NaH}_{2} \mathrm{PO}_{4} 1.25, \mathrm{NaHCO}_{3}$ 30 , Hepes acid 20, Glucose 25, thiourea $2, \mathrm{C}_{6} \mathrm{H}_{7} \mathrm{NaO}_{6} 5, \mathrm{Na}-$ pyruvate $3, \mathrm{CaCl}_{2} 0.5$, and $\mathrm{MgCl}_{2} 10(\mathrm{pH}=7.35)$. Slices were then transferred to an immersion recording chamber and perfused with gassed solution $\left(30-34^{\circ} \mathrm{C}\right)$ at a rate of $1-2 \mathrm{ml} /$ min. The recording area was visualized under an Olympus BX50WI microscope (Olympus Optical, Tokyo, Japan). 
Bipolar platinum/iridium stimulation electrode of $50 \mu \mathrm{m}$ and the recording electrode were placed on stratum radiatum of hippocampal CA1 region to record synaptic activity. Recording glass microelectrodes of 3-5 $\mathrm{M} \Omega$ were filled with $\mathrm{NaCl} 3 \mathrm{mM}$. Extracellular postsynaptic field potentials (fPSPs) were amplified (EX1; DAGAN; Minneapolis, MN), bandpass filtered between $0.3 \mathrm{~Hz}$ and $1.0 \mathrm{kHz}$, and digitized at $10.0 \mathrm{kHz}$ (pCLAMP 9 software; Molecular Devices, Sunnyvale, CA). A stimulus intensity, which evoked halfmaximum amplitude fPSPs, was used. Baseline responses were recorded for at least $10 \mathrm{~min}$ with test stimuli given at a rate of $0.1 \mathrm{~Hz}$. The initial phase of the fPSP was used to quantify synaptic transmission; the slopes during the experiments are expressed as percentages of the baseline slope. CM-414 (200 nM) added to the external solution was perfused 15-20 min before LTP-induction protocol was applied, ie, high-frequency stimulation (HFS) consisting of $100 \mathrm{~Hz}$ trains delivered 4 times at $0.05 \mathrm{~Hz}$.

\section{PDE and HDAC Functional Activity In Vivo}

To confirm the ability of CM-414 to inhibit HDAC and PDE in the brain, the compound CM-414 (40 mg/kg) was administered to WT mice $(n=3)$. After $30 \mathrm{~min}$, mice were killed and their hippocampus was quickly dissected from the brains. Total tissue homogenates were obtained by homogenizing the hippocampus in a lysis buffer containing Tris- $\mathrm{HCl} 10 \mathrm{mM}, \mathrm{NaF} 1 \mathrm{mM}, \mathrm{NaVO}_{4} 0.1 \mathrm{mM}$, (SDS) 2\%, and protease inhibitors. Western blot was carried out to analyze AcH3-K9 and pCREB-Ser133.

\section{Pharmacokinetic Study of CM-414 in Plasma Samples}

See Supplementary Materials and Methods.

\section{Animals and Chronic Treatments}

Transgenic mice (Tg2576) overexpressing hAPP carrying the Swedish (K670N/M671L) familial AD mutation under control of the prion promoter (Hsiao et al, 1996) were used. Mice were on an inbred C57BL/6/SJL genetic background. Animals were housed 4-5 per cage with free access to food and water, and maintained in a temperature-controlled environment on a $12 \mathrm{~h}$ light-dark cycle. The 14-16-monthold Tg2576 female mice were treated once daily with CM-414 (40 mg/kg, intraperitoneal (i.p.)) or vehicle for 4 weeks followed by a washout period of 4 weeks before killing the animals for biochemical analysis. Behavioral and biochemical studies were performed comparing transgenic mice treated with CM-414 with vehicle.

\section{Behavioral Studies}

Behavioral studies were carried out during light time (from 0900 to $1400 \mathrm{~h}$ ). Protocols were approved by the Ethical Committee of the University of Navarra (in accordance with the European and Spanish Royal Decree 1201/2005).

Fear conditioning test. To evaluate the effects of drugs on cognitive function after 2 weeks of treatment, fear conditioning paradigm was used (Ricobaraza et al, 2012).
Freezing scores were expressed as percentage. The conditioning procedure was carried out in a StartFear system (Panlab, Barcelona, Spain).

Morris water maze test (MWM). After 3 weeks of treatment, we used the MWM test to evaluate the working and reference memory function in Tg2576 mice (Garcia-Barroso et al, 2013). In addition, after a 4-week washout period of the drugs, a reversal phase of MWM was carried out. In this phase the platform was placed in the opposite quadrant of the tank and the hidden platform training during 5 consecutive days (four trials per day) was performed. All cues remained in their original positions. Memory retention was analyzed in a probe at day 6. Mice were monitored by a camera mounted in the ceiling directly above the pool, and all trials were recorded using an HVS water maze program for subsequent analysis of escape latencies, swimming speed, path length, and percent time spent in each quadrant of the pool during probe trials (Analysis Program WaterMaze3, Actimetrics, Evanston, IL). All experimental procedures were performed blind to groups. Animals were killed $24 \mathrm{~h}$ after the last probe.

\section{Determination of $\mathrm{A} \beta$ Levels}

Parietotemporal cortical $\mathrm{A} \beta_{42}$ levels were measured by using a sensitive sandwich ELISA kit (Invitrogen, Camarillo, CA). We measured $\mathrm{A} \beta_{42}$ pool containing intracellular and membrane-associated $\mathrm{A} \beta_{42}$ that may be more closely related to the expression of $\mathrm{AD}$ signs than other measured $\mathrm{A} \beta_{42}$ species (Steinerman et al, 2008). Tissue was homogenized in a buffer containing SDS $2 \%$, Tris- $\mathrm{HCl}(10 \mathrm{mM}, \mathrm{pH} 7.4)$, protease inhibitors (Complete Protease Inhibitor Cocktail, Roche), and phosphatase inhibitors ( $0.1 \mathrm{mM} \mathrm{Na}_{3} \mathrm{VO}_{4}, 1 \mathrm{mM}$ $\mathrm{NaF}$ ). The homogenates were sonicated for $2 \mathrm{~min}$ and centrifuged at $100000 \mathrm{~g}$ for $1 \mathrm{~h}$. Aliquots of supernatant were directly diluted and loaded onto ELISA plates in duplicate. The assays were performed according to the manufacturer's instructions.

\section{Immunoblotting}

For western blot analysis of APP-derived fragments, protein extracts were mixed with tricine sample buffer $1: 2$ (Bio-Rad, Hercules, CA) and $2 \% \beta \mathrm{ME}$, and after that they were boiled for $5 \mathrm{~min}$. Proteins were separated in a Criterion Tris-Tricine $10-20 \%$ gradient precast gel (Bio-Rad) and transferred to a PVDF membrane with $0.2 \mu \mathrm{m}$ removal rating (Hybond LFP, Amersham Biosciences, Little Chalfont, UK).

For analysis of pTau, aliquots of the protein extracts were mixed with XT sample buffer plus XT reducing agent (Bio$\mathrm{Rad}$ ) and boiled for $5 \mathrm{~min}$. Proteins were separated in a Criterion Bis-Tris 4-12\% gradient precast gel (Bio-Rad). For western blot analysis of synaptic plasticity proteins, histones, pCREB, and tubulin, protein samples were mixed with $6 \times$ Laemmli sample buffer and resolved onto SDS-polyacrylamide gels and transferred to nitrocellulose membrane.

In all cases, the membranes were blocked with $5 \%$ milk, $0.05 \%$ Tween-20 in Tris-buffered saline (TBS) followed by overnight incubation with the following primary antibodies: mouse monoclonal 6E10 (amino acids $1-16$ of $\mathrm{A} \beta$ peptide, 
$1: 1000$, Covance, San Diego, CA), mouse monoclonal antip-Tau AT8 (1 : 1000; Thermo Fisher Scientific, Rockford, IL), mouse monoclonal anti-tau (1:5000, clone Tau46, SigmaAldrich, St Louis, MO), rabbit polyclonal anti-pGluA1, rabbit polyclonal anti-GluA2/3, rabbit polyclonal anti-GluN2A, rabbit polyclonal anti-GluN2B, mouse monoclonal antiPSD95 ( 1 : 1000, Millipore, Billerica, MA), rabbit monoclonal anti-acetylated $\mathrm{H} 3$ (Lys9), rabbit monoclonal anti-pCREB (Ser133), rabbit polyclonal anti-pGSK3 $\beta$ (Ser9) $(1: 1000$, Cell Signaling Technology, Danvers, MA), goat polyclonal antiEphB2R (1:500, Sigma-Aldrich), rabbit polyclonal antiGSK3 $\beta$ ( $1: 1000$, Santa Cruz Biotechnology, Santa Cruz, CA), mouse monoclonal anti-actin, mouse monoclonal antiacetylated-tubulin $(1: 20000$, Sigma-Aldrich), mouse monoclonal anti-pCaM Kinase II, $\alpha$ subunit, (Thr286), clone 22B1 ( $1: 1000$, Millipore), mouse monoclonal anti-CaM Kinase II (1:1000, Santa Cruz Biotechnology), and rabbit polyclonal anti-pERK1/2 (1:1000, Cell Signaling Technology) in the corresponding buffer. Following two washes in PBS/Tween20 or TBS/Tween-20 and one PBS or TBS alone, immunolabeled protein bands were detected by using HRPconjugated anti-rabbit, anti-mouse antibody (1:5000, Santa Cruz Biotechnology), or anti-goat (1:1500, Dako) antibody following an enhanced chemiluminescence system (ECL, GE Healthcare Bioscience, Buckinghamshire, UK), and autoradiographic exposure to Hyperfilm ECL (GE Healthcare Bioscience). Quantity One software v.4.6.3 (Bio-Rad) was used for quantification.

\section{Dendritic Spine Measurements}

A modified Golgi-Cox method was used (Glaser and Van der Loos, 1981; Ricobaraza et al, 2012). Pyramidal cells located within the CA1 region of the hippocampus and with consistent Golgi impregnation throughout untruncated dendrites were selected for morphometric analysis. For each mouse ( $n=4$ per group), 9 neurons (3 dendritic segments were measured per neuron, at least $30 \mu \mathrm{m}$ long) were analyzed.

\section{Affymetrix Microarray Hybridization and Data Analysis}

The hippocampi were dissected and RNA was extracted with TRIzol Reagent (Invitrogen) according to the manufacturer's instructions. As a last step of the extraction procedure, the RNA was purified with the RNeasy Mini-kit (Qiagen, Hilden, Germany). Before cDNA synthesis, RNA integrity from each sample was confirmed on Agilent RNA Nano LabChips (Agilent Technologies). The sense cDNA was prepared from $300 \mathrm{ng}$ of total RNA using the Ambion WT Expression Kit. The sense strand cDNA was then fragmented and biotinylated with the Affymetrix GeneChip WT Terminal Labeling Kit (PN 900671). Labeled sense cDNA was hybridized to the Affymetrix Mouse Gene 2.0 ST microarray according to the manufacturer's protocols and using GeneChip Hybridization, Wash, and Stain Kit. Genechips were scanned with the Affymetrix GeneChip Scanner 3000. Microarray data files were submitted to the GEO (Gene Expression Omnibus) database and are available under accession number GSE62240.

Both background correction and normalization were done using RMA (Robust Multichip Average) algorithm (Irizarry et al, 2003). Then, a filtering process was performed to eliminate low expression probe sets. Applying the criterion of an expression value of $>16$ in at least two samples for each experimental condition (hippocampi from mice treated with vehicle and CM-414, $n=4), 29850$ probe sets were selected. R/Bioconductor (Gentleman et al, 2006) was used for preprocessing and statistical analysis.

First, we applied one of the most widely used methods to find out the probe sets that showed significant differential expression between experimental conditions, LIMMA (Linear Models for Microarray Data) (Smyth, 2004). Genes were selected as significant using $p$-value of $<0.01$ as threshold. Using false discovery rate (FDR) method to correct for multiple hypotheses testing, no significant results were obtained.

Next, a functional enrichment analysis of Gene Ontology (GO) categories was carried out using standard hypergeometric test (Subramanian et al, 2005) and the biological knowledge extraction was complemented through the use of Ingenuity Pathway Analysis (Ingenuity Systems, www.ingenuity.com), a database that includes manually curated and fully traceable data derived from literature sources. However, the small number of enriched functions and pathways and the lack of relationships among differentially expressed genes in the network analysis of IPA suggested that by using this bioinformatics workflow we were not able to obtain robust and reliable results.

Alternative approaches based on the enrichment of gene sets using the ranked list of genes ( $p$-value, FDR, fold change, and so on) in a microarray experiment can be used in order to detect functional enrichments associated with small changes in the expression of groups of genes. The fold change ranked list of genes was used as input to the nonparametric Kolmogorov-Smirnoff rank test as implemented in the GSEA (Gene Set Enrichment Analysis) software (Subramanian et al, 2005). Gene categories were selected from MsigDB database performing a query using keywords of interest (learning, creb, amyloid, aging, alzheimer, epigenetic, synaptic, and neuron). A total of 95 gene sets were selected for further analyses. The $p$-values for each gene set were computed based on 2500 permutation iterations. We select those categories enriched with $p<0.05$ in the upregulated genes. The selection of genes of interest was based on the leading edge analysis of the enriched categories. The biological knowledge extraction was complemented through the use of Ingenuity Pathway Analysis (Ingenuity Systems, www.ingenuity.com), a database that includes manually curated and fully traceable data derived from literature sources.

\section{Data Analysis and Statistical Procedures}

The data were analyzed with SPSS for Windows, version 15.0 (SPSS, Chicago, IL), and unless otherwise indicated, the data are expressed as means \pm SEM. Normal distribution of data was checked by the Shapiro-Wilk test.

In the MWM, latencies to find the platform were examined by two-way repeated measures ANOVA test (genotype $\times$ trial) to compare the cognitive status in WT mice and Tg2576 mice. Similarly, the treatments effect in spatial memory was also examined by a two-way repeated measures 
a<smiles>C=C1CC(C#N)C1C(=O)OCC</smiles><smiles>CCCc1nn(C)c2c(=O)[nH]c(-c3cc(I)ccc3OCC)nc12</smiles><smiles>CCCc1nn(C)c2c(=O)[nH]c(-c3cc(CC4CC(C(=O)NO)C4)ccc3OCC)nc12</smiles><smiles>CCCc1nn(C)c2c(=O)[nH]c(-c3cc(CC4CC(C(=O)O)C4)ccc3OCC)nc12</smiles><smiles>CCCc1nn(C)c2c(=O)[nH]c(-c3cc(CC4CC(C(=O)OCC)C4)ccc3OCC)nc12</smiles>

b

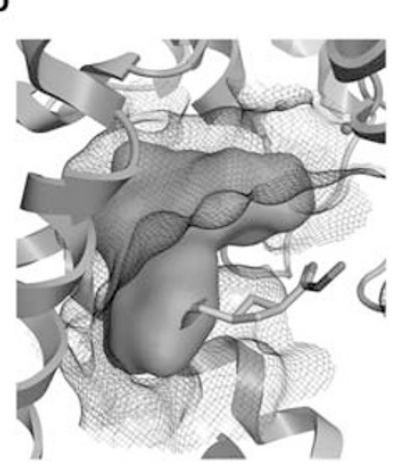

d

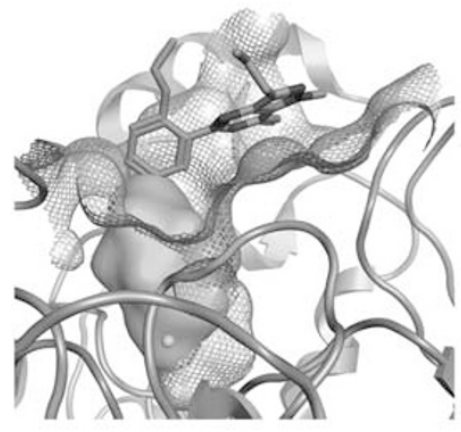

C

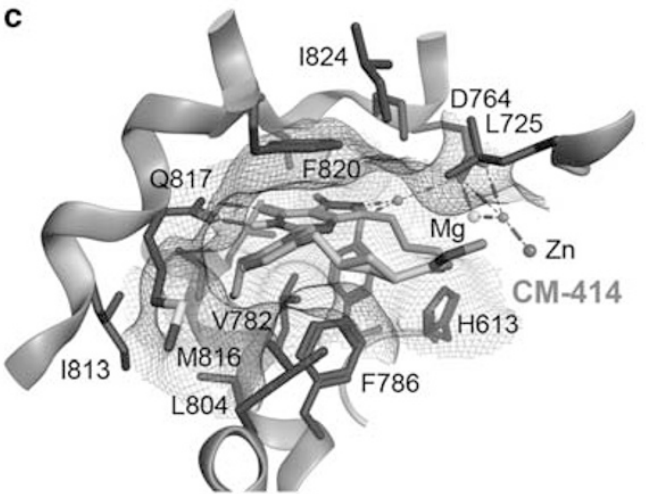

e

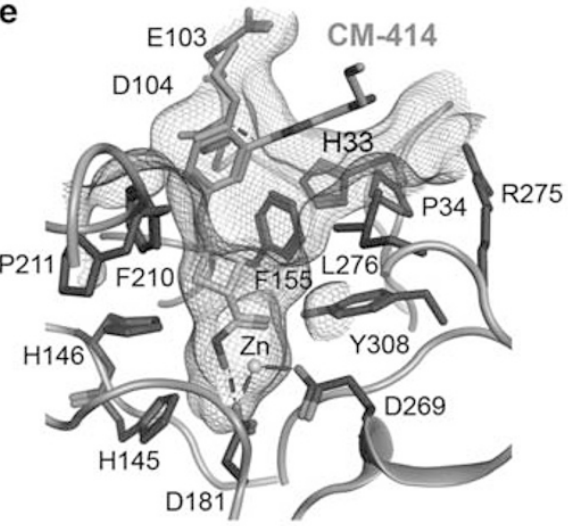

f PDEs enzyme activity

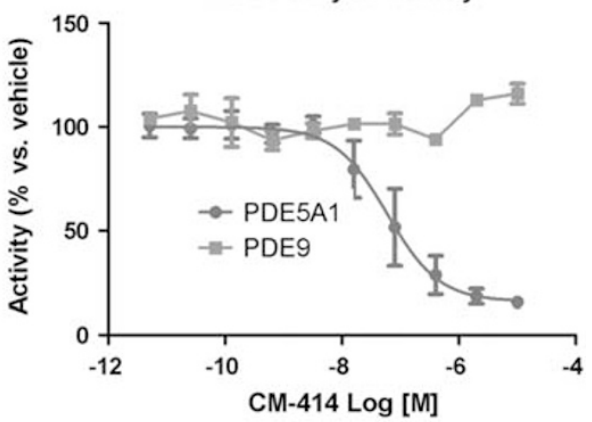

g

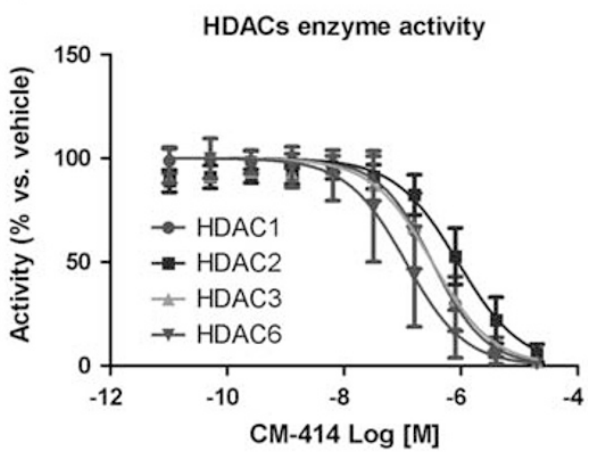

h

\begin{tabular}{l|cccccc} 
& HDAC1 & HDAC2 & HDAC3 & HDAC6 & PDE5 & PDE9 \\
\hline CM-414 & 6.51 & 6.31 & 6.49 & 7.04 & 7.22 & $>5$ \\
CM-545 (cis) & 6.65 & 6.14 & 6.55 & 6.84 & 7.47 & $>5$ \\
CM-546 (trans) & 6.49 & 5.91 & 6.62 & 6.90 & 7.35 & $>5$
\end{tabular}

Figure I Design, synthesis, and validation of CM-4I4, a new dual inhibitor of HDAC and PDE5. (a) CM-4I4 formula and synthesis, (b, c) CM-4I4 bound to PDE5, and (d, e) CM-4I4 bound to HDAC2. (f) Dose-response curves of CM-4I 4 against PDE5AI (violet) and PDE9A (red); corresponding IC 50 values are $60 \mathrm{nM}$ and $>10 \mu \mathrm{M}$. (g) Dose-response curves of CM-4I 4 inhibition against HDACl (blue), HDAC2 (dark blue), HDAC3 (light blue), and HDAC6 (green); corresponding $\mathrm{IC}_{50}(\mathrm{nM})$ values are $310,490,322$, and $9 \mathrm{I} \mathrm{nM}$ respectively. (h) plC $\mathrm{C}_{50}$ values of $\mathrm{CM}-4 \mid 4$ and its cis $(\mathrm{CM}-545)$ and trans $(\mathrm{CM}-546)$ isomers against HDAC and PDE isoforms. A full color version of this figure is available at the Neuropsychopharmacology journal online. 
ANOVA test (treatment $\times$ trial) followed by post hoc Scheffe's analysis. When two groups were compared, Student's $t$-test was used, whereas when more than two experimental groups were compared, one-way ANOVA followed by post hoc Scheffe's test was used. Each biochemical assay was repeated at least three times and the data were analyzed using one-way ANOVA followed by post hoc Scheffe's test.

\section{RESULTS}

\section{Design and Synthesis of a First-in-Class Dual Inhibitor of HDAC and PDE5: CM-414}

Knowledge- and structure-based approaches have guided us to design and identify a first-in-class dual inhibitor of HDACs and PDE5 that fulfilled our target compound profile. Based on reported structure-activity relationships (SARs), data regarding HDAC (Kalin and Bergman, 2013; Miller et al, 2003) and PDE5 inhibition (Manallack et al, 2005), and structural information that included the X-ray co-crystal structures for the HDAC2-vorinostat complex (PDB 4LXZ) (Lauffer et al, 2013) and PDE5-sildenafil complex (PDB 1TBF) (Zhang et al, 2004), we designed and synthesized compounds to interact with both HDAC (class I and HDAC6) and PDE5. Consequently, a novel series of pyrazolopyrimidinones were designed and synthesized that bore key chemical functionalities covering the critical pharmacophoric features (Figure 1a-e and Supplementary Figure S1). Detailed exploration of this series, which included more than 100 compounds, confirmed their dual activity against HDACs and PDE5 (more information regarding this novel series is reported in our patent; Cuadrado Tejedor et al, 2014; the patent WO 2014/131855 A1 relates to the results present in the paper. Hence, we focused more specifically on compounds that fulfilled two preestablished dual activity criteria: (1) moderate activity against HDAC class I isoforms $\left(\mathrm{IC}_{50}\right.$ for HDAC1, HDAC2, and HDAC3 > $300 \mathrm{nM}$ ); and (2) potent inhibition of HDAC6 and PDE5 $\left(\mathrm{IC}_{50 \mathrm{~s}}<100 \mathrm{nM}\right)$. Furthermore, we were interested in molecules with short residence times ( $<60 \mathrm{~min}$ at $\mathrm{HDAC} 1)$ and thus only molecules meeting these thresholds were selected for further study.
Extensive multifactorial optimization of these molecules through medicinal chemistry, ADME studies (Absorption, Distribution, Metabolism, and Excretion properties), and cardiovascular safety and toxicity analyses highlighted CM-414 as an interesting pharmacological tool (Figure 1a and Supplementary Table S1). CM-414 had an $\mathrm{IC}_{50}$ against HDAC1, HDAC2, HDAC3, and HDAC6 of 310, 490, 322, and $91 \mathrm{nM}$, respectively, and its activity against PDE5 was $60 \mathrm{nM}$ (Figure 1f-h). Its corresponding enantiomers (CM-545 and CM-546) had equipotent primary activity as CM-414 (Figure 1h), and therefore we focused on the racemic compound (CM-414). Importantly, the residence time of CM-414 at HDAC1 was 35 min when measured by the jump dilution approach (Copeland et al, 2011). CM-414 bears a hydroxamic acid moiety that has been described as an effective metal-binding group for a variety of metalloenzymes. For this reason, the activity of CM-414 on two representative of matrix metalloproteases (MMP-3 and MMP-10) was also evaluated, producing an $\mathrm{IC}_{50}>10 \mu \mathrm{M}$ for both targets. The effects of CM-414 on PDE9 were also assessed (a major phosphodiesterase isoform that also hydrolyses cGMP) and its activity was $>10 \mu \mathrm{M}$. In addition, CM-414 did not inhibit class IIa isoforms $\left(\right.$ IC $_{50}>10 \mu \mathrm{M}$ for all four isoforms) or, expectedly, had mid-nanomolar activity against HDAC8 (640 nM, class I) and HDAC11 (550 nM, class IV) and low micromolar activity against HDAC10 (2400 nM, class IIb) (Supplementary Table S1). Together, these results suggest that this inhibitor has minimal promiscuity against related targets. Accordingly, we appear to have designed and synthesized a novel and selective dual chemical probe that fitted the original requirements for primary activity: moderate HDAC class I inhibition but potent activity against HDAC6 and PDE5, with a short residence time.

\section{The Chemical Probe, CM-414, Has Potent In Vitro and Ex Vivo Functional Activities}

Although the $\mathrm{IC}_{50}$ values of CM-414 for class I HDACs are higher than $300 \mathrm{nM}$ (Figure 1g), the synergistic effect of joint HDAC and PDE5 inhibition (Cuadrado-Tejedor et al, 2015) led to a significant increase in histone 3 lysine 9 (AcH3K9) acetylation in WT neurons (12-15 DIV) exposed to CM-414

\footnotetext{
Figure 2 CM-4I4 shows potent in vitro and ex vivo functional activities. (a) Western blots showing histone 3 acetylation at lys 9 (AcH3K9) levels in wild-type

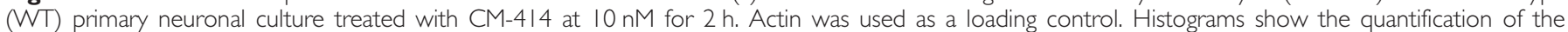

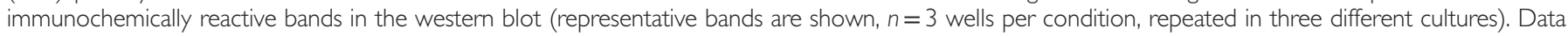

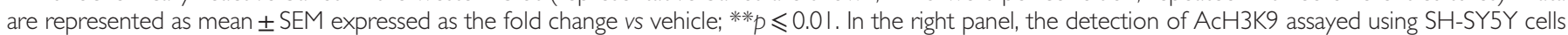

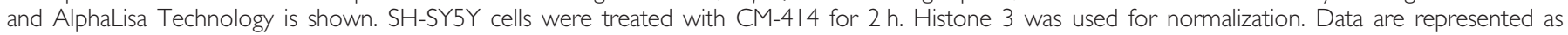

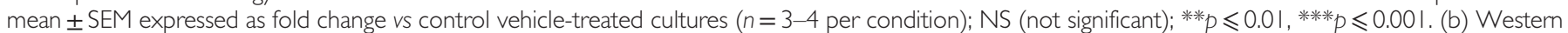

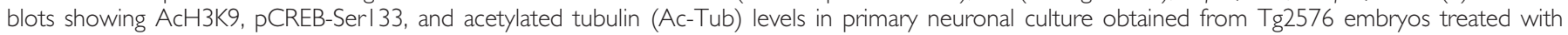

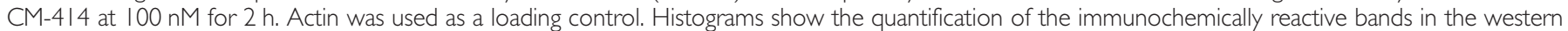

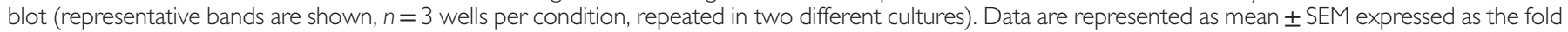

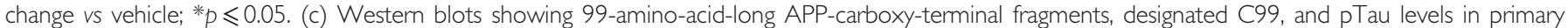

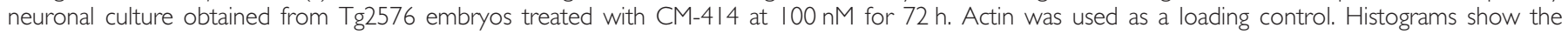

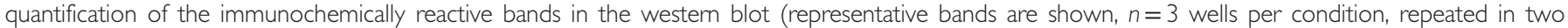

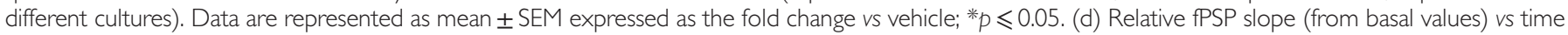

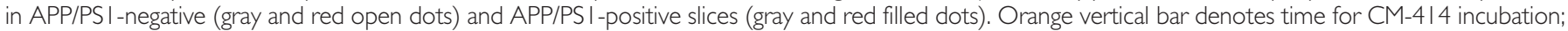

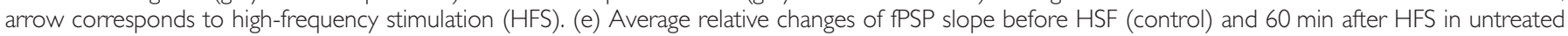

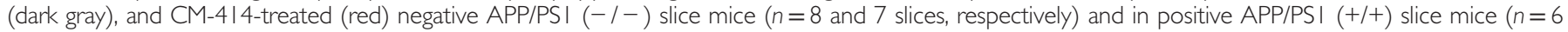

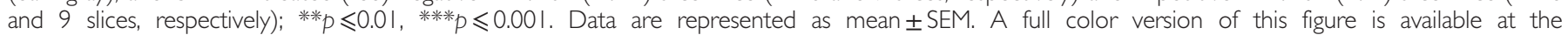
Neuropsychopharmacology journal online.
} 
at $10 \mathrm{nM}$ for $2 \mathrm{~h}$ (Figure 2a, left panel). The same concentration $(10 \mathrm{nM})$ was used in Tg2576 neurons (12-15 DIV); however, may be because of lower basal levels of $\mathrm{AcH} 3 \mathrm{~K} 9$ found in these neurons and/or different efficacy of the compound in these conditions, no effect was observed (Supplementary Figure S2). The synergistic effect of targeting simultaneously HDAC and PDE5 inhibition on histone acetylation was confirmed in SH-SY5Y neuroblastoma cells using Alpha Technology, monitoring the induction of $\mathrm{AcH} 3 \mathrm{~K} 9$ by CM-414 in a dose-dependent manner and witnessing a significant increase from $64 \mathrm{nM}$ (Figure 2a, right panel).

Next, CM-414 (100 nM) was tested on cultured Tg2576 neurons (12-15 DIV). As depicted in Figure 2b, a significant increase was observed in the case of AcH3K9, whereas a clear tendency to increase was found for pCREB-Ser133 $(p=0.06)$ and Ac-Tub $(p=0.07)$ levels after $2 \mathrm{~h}$ of exposure to CM-414, thereby confirming the functional activity of this compound in vitro against all its targets (HDAC class I, PDE5, and HDAC6). Finally, to analyze whether the simultaneous
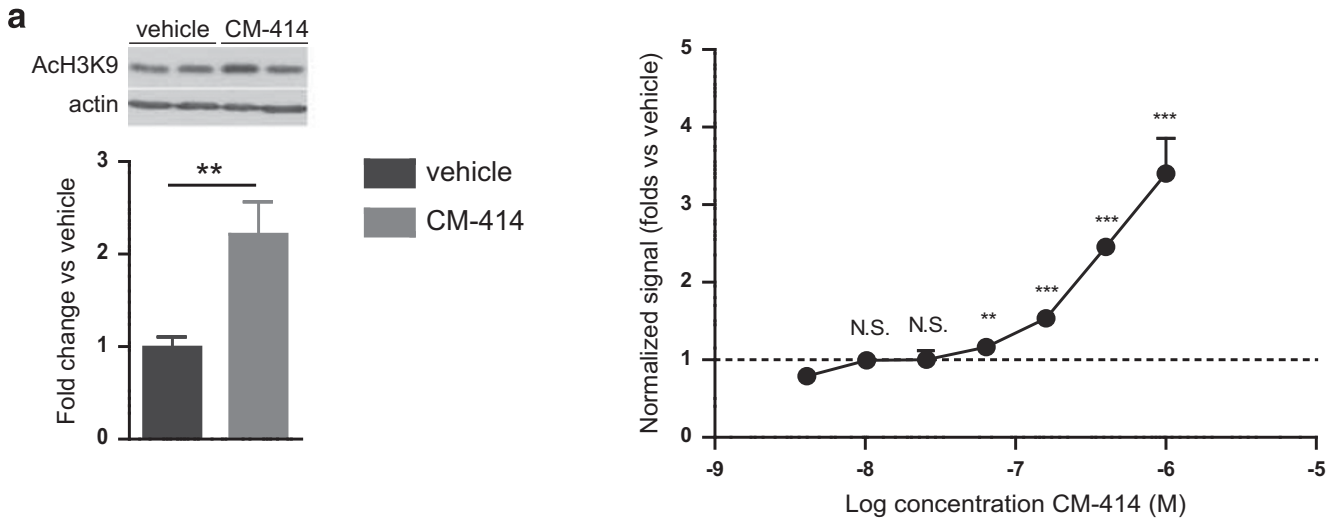

b

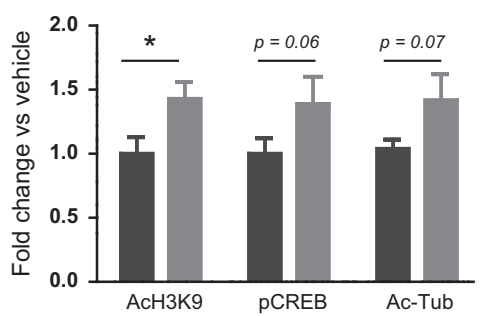

c

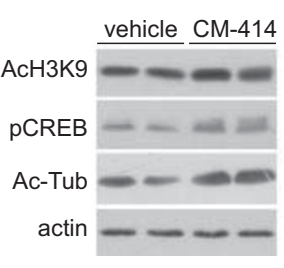

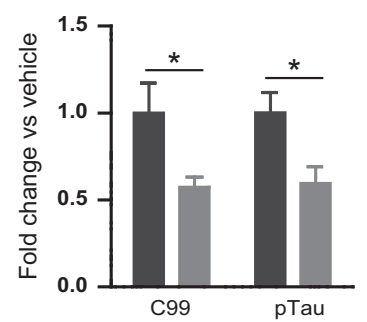

vehicle

CM-414

d

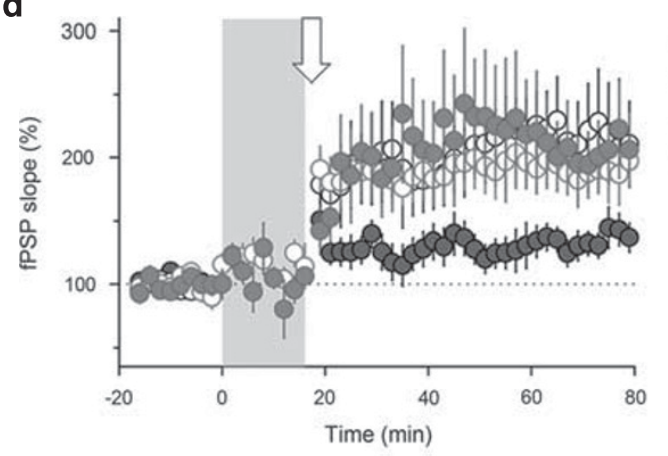

O APPIPS $1 \%$

O APPIPS $1 \%$ \& CM-414

- APPIPS1 $1^{+/+}$

- APP/PS $1^{+/+} \& \mathrm{CM}-414$

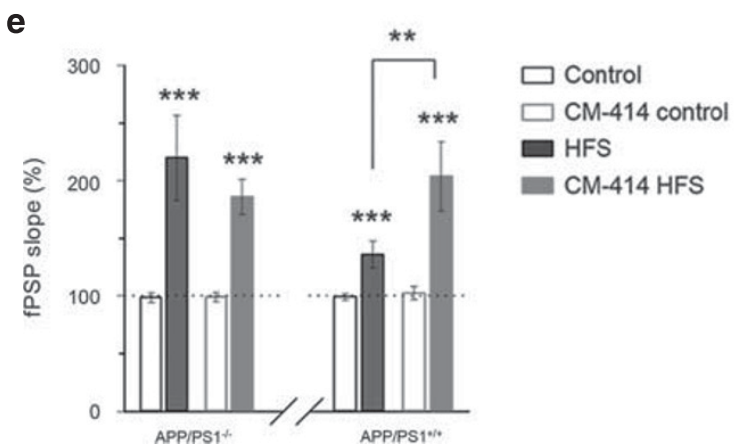


inhibition of these enzymes had any effect on AD-related markers, Tg2576 neurons (21 DIV) were used to study the effect of CM-414 on hAPP processing and pTau. The processing of hAPP by the amyloidogenic pathway was determined in western blots by evaluating the expression of the APP-CTFs, designated C99, the $\mathrm{A} \beta_{42}$ precursor. A decrease in C99 levels was observed in cells exposed to $100 \mathrm{nM}$ CM-414 (Figure 2c). The effect of this compound on pTau in the same samples was assessed with the phosphospecific AT8 antibody that recognizes the hyperphosphorylated Ser202/Thr205 epitopes. A decrease in pTau was observed following exposure to CM-414 (100 nM, Figure 2c) relative to the untreated control cells.

At the functional level, we investigated the ability of CM-414 to modulate the strength of LTP, a well-known cellular mechanism that affects memory processes in APP/ PS1 mice (7-9 months) (Bliss and Collingridge, 1993). Preincubation of hippocampal slices with CM-414 (200 nM) rescued the synaptic plasticity impairment evident in APP/PS1 AD mice, with synaptic potentiation resembling that observed in the control (untreated) slices (Figure $2 \mathrm{~d}$ and e). Remarkably, CM-414 treatment did not affect the magnitude of LTP in APP/PS1 WT slices (Figure 2d and e). These results were consistent with earlier theoretical (Smolen et al, 2014) and experimental (Cuadrado-Tejedor et al, 2015) studies where a combination of HDAC and PDE inhibitors produced robust potentiation of synaptic transmission.

\section{CM-414 Displays Symptomatic and Disease-Modifying Efficacy In Vivo in AD Tg2576 Mice}

Before evaluating the in vivo efficacy of the dual inhibitor, we examined the therapeutic window of this molecule and its pharmacokinetic (PK) parameters. We compared the in vitro activity of CM-414 (see above, Supplementary Table S1) with its toxicity in the nontumoral hepatic THLE-2 cell line, in peripheral blood mononuclear cells (PBMCs: obtained from healthy donors), and in neurons and glia from WT mice $\left(\mathrm{LC}_{50 \mathrm{~s}}>100 \mu \mathrm{M}\right.$ after $24 \mathrm{~h}$, Supplementary Table S1). CM-414 had an acceptable therapeutic window in vitro ( $>3$ log units in the worst scenario and the $\mathrm{EC}_{50}$ of pTau was $100 \mathrm{nM}$ ), although its moderate passive diffusion in vitro $(\mathrm{Pe}=15.7 \mathrm{~nm} / \mathrm{s}$, PAMPA assay: Supplementary Table S1) suggested suboptimal penetration of the blood-brain barrier (BBB) (Supplementary Table S1), and thus a high dose was required for an effective concentration to reach the central nervous system (CNS). Therefore, before performing PK studies, we explored different doses to identify which one achieved the desired functional response in the CNS; an optimal dose of $40 \mathrm{mg} / \mathrm{kg}$ (i.p.) was selected. Indeed, $30 \mathrm{~min}$ after administering this dose to mice there was an increase in AcH3K9 and in pCREB-Ser133 phosphorylation in the hippocampus (Supplementary Figure S3c). The corresponding PK studies (Supplementary Table S1 and Supplementary Figure S3a and b) confirmed certain parameters, such as the short half-life $\left(t_{1 / 2}\right.$ of $\left.2.8 \mathrm{~h}\right)$ and acceptable brain concentration $(248 \mathrm{nmol} / \mathrm{kg})$, parameters suitable to ensure the expected functional responses (see above, Supplementary Figure S3c). Despite its poor penetration, the $\operatorname{logBB}$ of CM-414 was -1.87 , with a maximum plasma concentration
$\left(\mathrm{C}_{\max }\right.$ is $\left.18.5 \mu \mathrm{M}\right)$ (Supplementary Figure $\mathrm{S} 3 \mathrm{a}$ and $\mathrm{b}$ ) still far from the $\mathrm{LC}_{50}$ values for THLE-2 cells and PBMCs $(>100 \mu \mathrm{M})$, evidence of an adequate therapeutic window in vivo ( $>0.7$ log unit). In fact, no physical indications of sickness were observed. Based on these results, CM-414, at $40 \mathrm{mg} / \mathrm{kg}$, was examined in further in vivo studies. A 5-day treatment with CM-414 to 12-month-old Tg2576 mice resulted in a significant increase in $\mathrm{AcH} 3 \mathrm{~K} 9$ in the mice brain cortex, confirming that the compound reaches the brain at enough concentration to obtain a functional response in this mouse model (Supplementary Figure S4).

Then, we analyzed whether CM-414 might effectively reverse the cognitive impairment in Tg2576 mice. Accordingly, studies were performed on 14-16-month-old Tg2576 female mice treated daily with CM-414 (40 mg/kg) or vehicle, as indicated in Figure 3a, to confirm whether the effect of CM-414 could be maintained after a 4-week washout period. A 2-week treatment with CM-414 rescued the memory impairment exhibited by $\mathrm{Tg} 2576$ mice in the fear conditioning (FC) test (Figure 3b), showing a freezing response similar to WT mice (Supplementary Figure S5a). Spatial memory was also assessed after 3 weeks of treatment in the MWM and no significant differences were observed during the visible-platform training phase, indicating a comparable ability of the animals to perform the task (Figure 3c). During the hidden platform phase, Tg2576 animals that received the vehicle alone performed worse than the CM-414 treatment group (Figure 3d); escape latencies were found to be similar in CM-414-treated mice and WT controls (Supplementary Figure S5b). Moreover, during the retention tests, the animals that received CM-414 spent more time in the correct quadrant on days 7 and 9 than those that received the vehicle alone, demonstrating a positive effect of CM-414 on spatial memory (Figure $3 \mathrm{e}$ ).

A reversal phase of the MWM test was carried out following a 4-week washout period, and the Tg2576 mice treated with CM-414 showed significantly shorter escape latencies than the $\mathrm{Tg} 2576$ mice that received the vehicle alone (Figure 3f). Memory retention on day 6 showed that the $\operatorname{Tg} 2576$ mice that received the vehicle alone spent significantly less time in the target quadrant than those that received CM-414 (Figure $3 g$ ).

\section{Effects of CM-414 on Pathological Markers of AD in Aged-Tg2576 Mice after a 4-Week Washout Period}

The soluble $\mathrm{A} \beta_{42}$ in SDS protein extracts from the parietotemporal cortex of Tg2576 animals was assessed by ELISA and exposure to CM-414 produced a significant decrease in this peptide (Figure 4a). We explored APP processing in the same extracts and CM-414 administration to Tg2576 mice produced a decrease in APP and CTF-C99 that was evident in western blots (Figure 4b). Similarly, CM-414 produced a significant decrease in pTau in Tg2576 mice as witnessed when the same extracts were probed with the pTau-specific antibody (Ser-202/Thr-205) and normalized to total tau (T46, Figure 4b). Interestingly, the decrease in pTau levels parallels with a significant increase in the inactive form of glycogen synthase kinase-3 $\beta$ (GSK3 $\beta$ ) (GSK3 $\beta$ phosphorylated at Ser9; Figure $4 \mathrm{c}$ ), one of the main kinases involved in the pathogenic mechanisms of $\mathrm{AD}$ through the phosphorylation at multiple sites of tau 


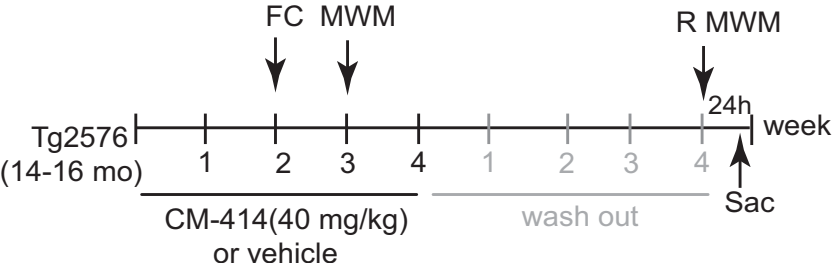

b

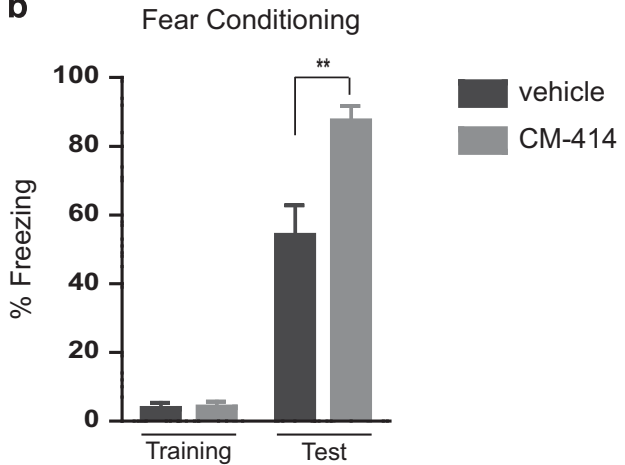

d

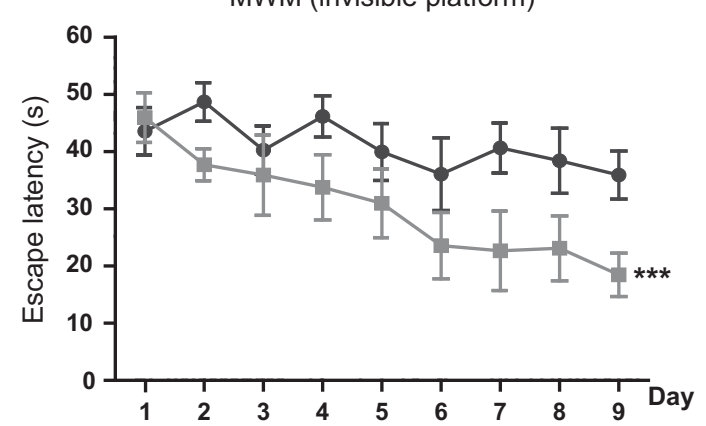

f

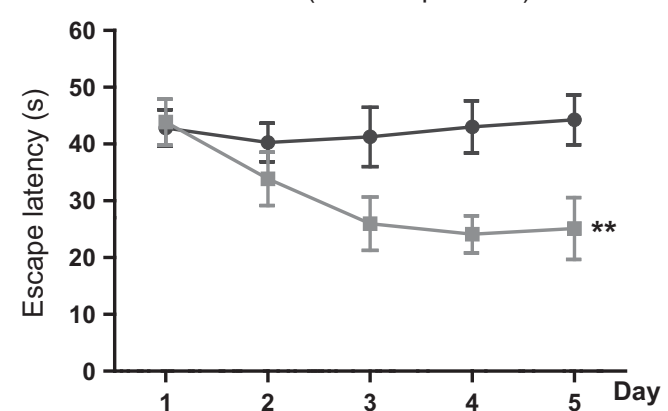

C MWM (visible platform)

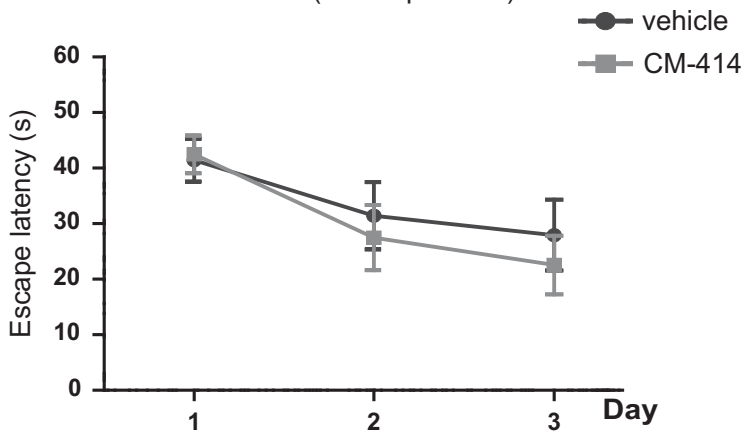

e

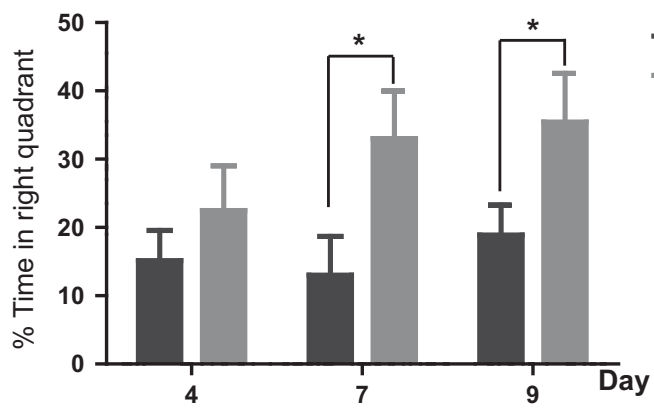

g $\quad$ MWM (probe test)

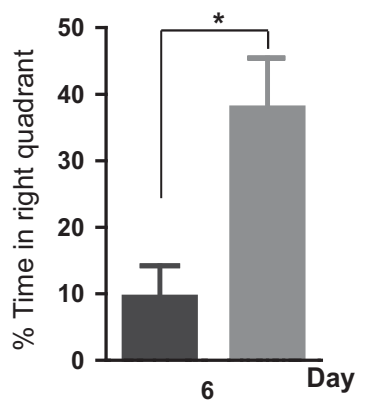

Figure 3 Chronic treatment (4 weeks) with CM-4I 4 reversed learning deficits in aged Tg2576 mice. (a) Scheme showing timeline for treatment, behavioral tasks, and killing of mice. FC, fear conditioning, MWM, Morris water maze, RMWM, reversal MWM, Sac, sacrificed. (b) Freezing behavior from Tg2576 mice treated with vehicle or CM-4I4. Data represent the percentage of time of freezing during training and during a 2 min test. (c) No significant differences in escape latency were detected between groups during any of the 3 days of visible-platform training. (d) Escape latency of the hidden platform in the MWM test for the Tg2576 mice treated with vehicle or CM-4 I4. (e) Percentage of time spent in correct quadrant during the probe test (days 4, 7, and 9). ( $f$ ) Escape latency during the reversal MWM (rMWM) test for the Tg2576 mice treated with vehicle or CM-4I 4 after the washout period. (g) Percentage of time spent in correct quadrant during the probe test after rMWM phase (day 6). In all figures results are expressed as mean \pm SEM $(n=8-1 \mid$ per group); $* p \leqslant 0.05$, *** $p \leqslant 0.01$, , **** $p \leqslant 0.001$.

(Mandelkow et al, 1992). As a decrease in APP may result detrimental for its contribution to synaptic plasticity and hippocampus-dependent memory (Goguel et al, 2011; Weyer et al, 2011), we analyzed the effect of CM-414 on APP in WT mice. As depicted in Supplementary Figure S6a, we demonstrated that CM-414 did not affect APP or C99 levels in WT mice after 5 days of treatment, whereas the same treatment significantly reduced the levels of both APP and $\mathrm{C} 99$ and $\mathrm{A} \beta_{40}$ in Tg2576 mice (Supplementary Figure S6b).

As Tg2576 mice experience synaptic dysfunction and loss, which occurs in relation to the earliest signs of cognitive impairment (Ricobaraza et al, 2012), we assessed whether the 
a

b

vehicle

CM-414
C
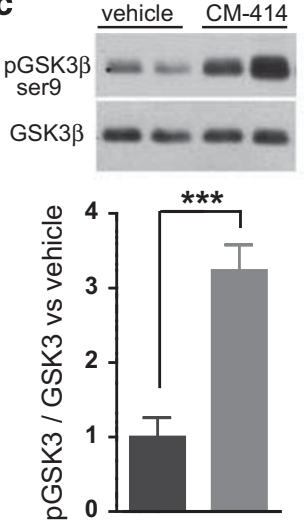

d
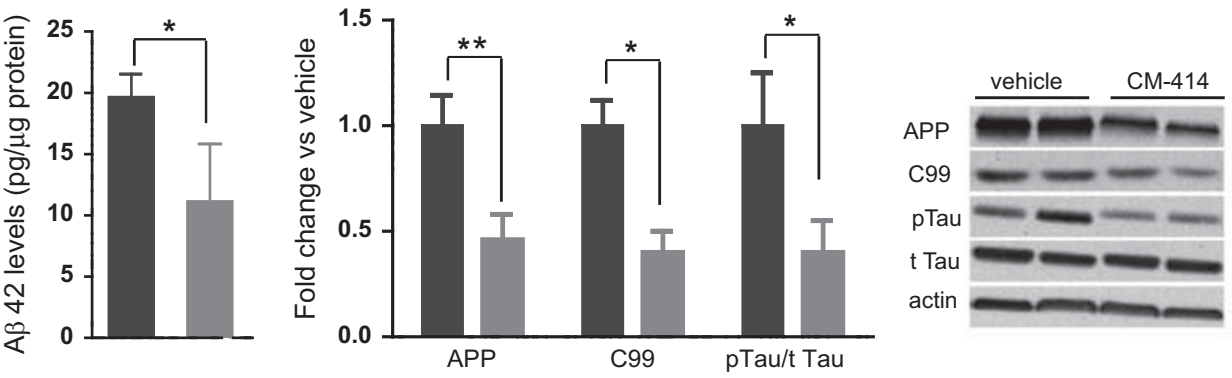

vehicle

CM-414

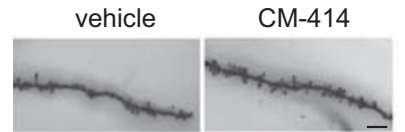

e
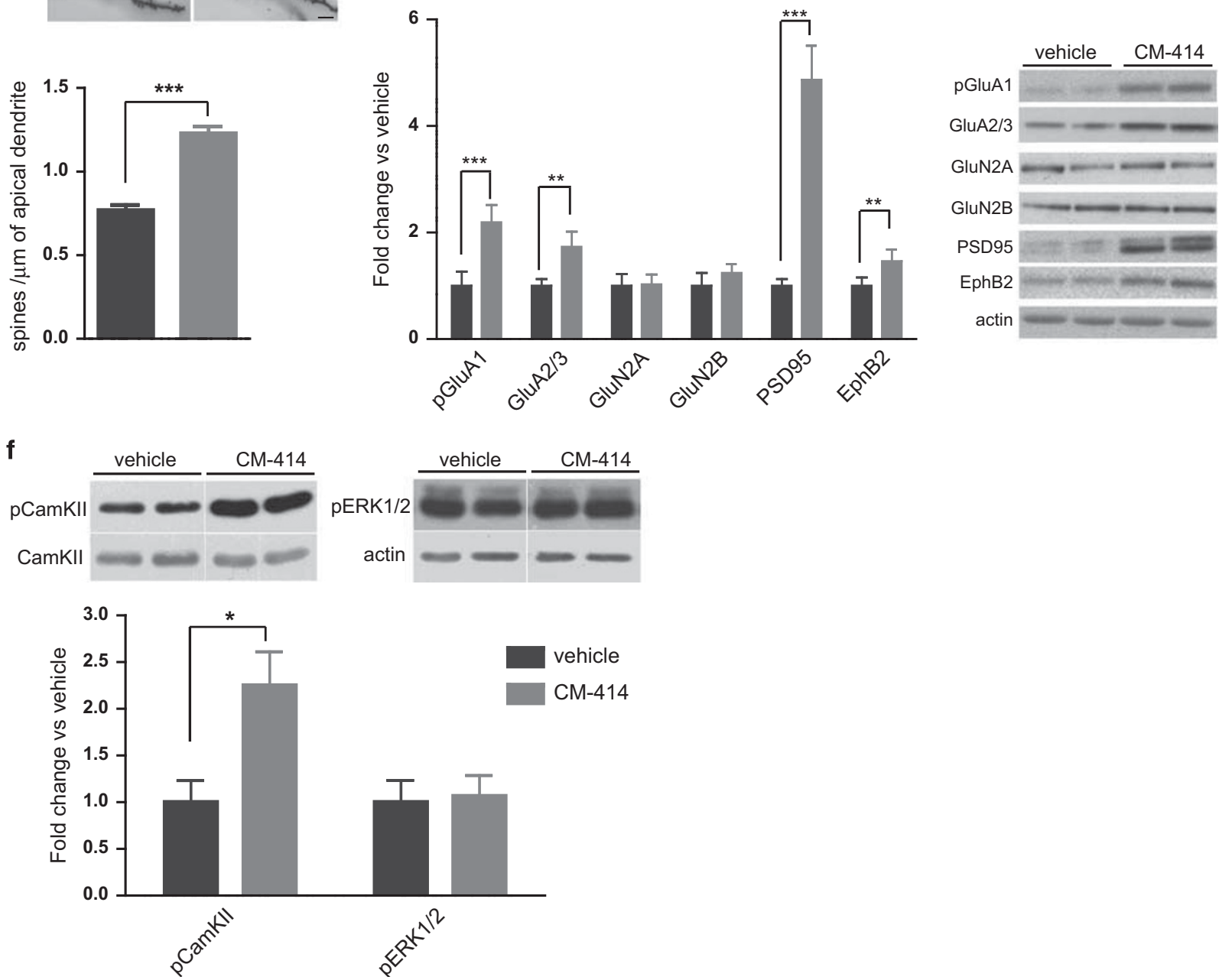

vehicle

CM-414

behavioral recovery induced by CM-414 was reflected by structural changes in dendritic spine density. Administration of CM-414 increased the spine density on apical CA1 dendrites from these mice (Figure 4d) and this was reflected by an upregulation of markers of synaptic plasticity when the pGluA1 and GluA2/3 AMPA receptor subunits, PSD95 and the EphB2 receptor tyrosine kinase, were assessed in western blots of SDS-soluble parietotemporal cortex tissue extracts (Figure 4e). Importantly, CM-414 induced the restoration of some of the downregulated genes in Tg2576 mice vs WT (pGluA1, GluA2/3, EphB2, and PSD95), whereas it did not modulate other genes such as GluN2B that show similar levels in WT and Tg2576 animals (Supplementary Figure S5c). It is important to note that pharmacological 


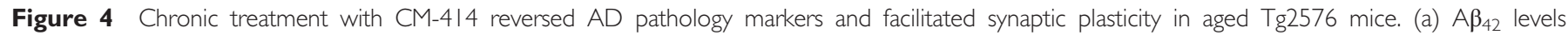

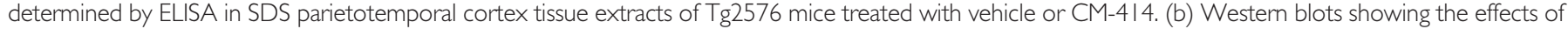

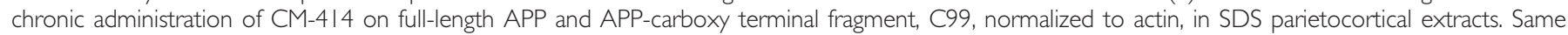

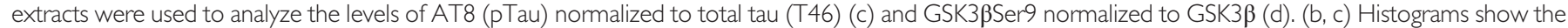

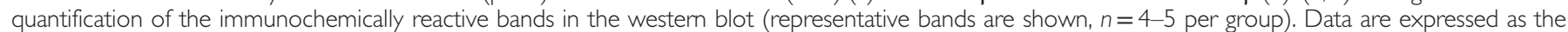

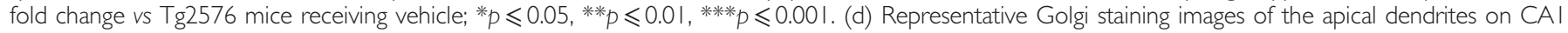

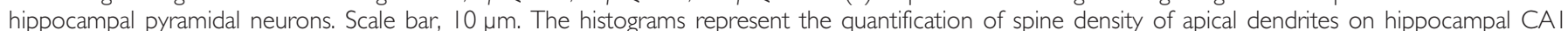

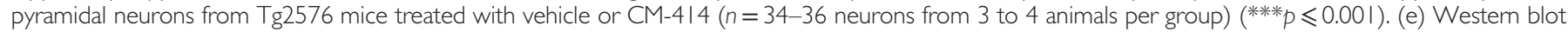

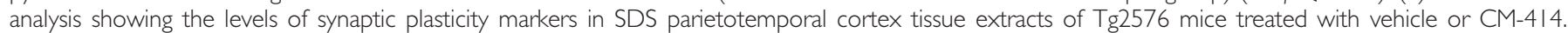

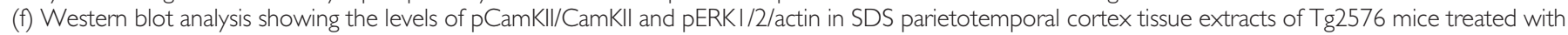

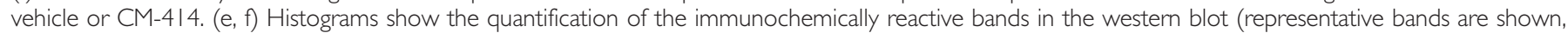
$n=5-8$ per group). Data are expressed as the fold change vs Tg2576 mice receiving vehicle; $* p \leqslant 0.05, * * p \leqslant 0.01, * * * p \leqslant 0.001$.

treatments that increase EphB2 expression have been proposed as a treatment for $\mathrm{AD}$ (Cisse et al, 2011), but to the best of our knowledge, there is still no pharmacological treatment that triggers an increase in EphB2 expression.

To further explore the mechanism underlying the improvement in memory function and spine formation, we analyzed the levels of phosphorylation of calcium/calmodulin-dependent protein kinase II (pCaMKII; Thr286) and of extracellular signal-related kinase $1 / 2$ (pERK1/2) that may also promote synaptic plasticity (Giese and Mizuno, 2013; Lucchesi et al, 2011; Vaillant et al, 2002). A significant increase was observed in the case of pCaMKII levels with no effects on pERK1/2 in the group of mice treated with CM-414 (Figure 4f). An increase in the levels of pCaMKII may be related to the increase in pGluA1 that promote its insertion at the synapse, facilitating memory function and the maintenance of long-term memories (Lisman et al, 2002; Bayer and Schulman, 2001).

Finally, we analyzed the effects of CM-414 on gene expression in the hippocampus of Tg2576 mice using Affymetrix microarray hybridization. First, we applied LIMMA to find out the probe sets that showed significant differential expression between experimental conditions (Smyth, 2004). Genes were selected as significant using $p<0.01$ as threshold (Supplementary Table S2). These results, which are available to the community via GEO (under accession number GSE62240), also include data generated from microarray comparing vorinostat (HDACi), tadalafil (PDE5i), and their combination with vehicle that correspond to our previous manuscript (Cuadrado-Tejedor et al, 2015). The number of differentially expressed genes (DEGs) based on the cutoff criteria $p \leqslant 0.01$ and the overlap of each contrast found after the different treatments are represented in the Venn diagram depicted in Supplementary Figure S7. Despite the lack of overlap among the DEG genes for each treatment, the analysis identified common enriched pathways and gene signatures associated with synaptic transmission in the upregulated genes in mice hippocampi by combined therapy (vorinostat and tadalafil) and CM-414 treatment and not with individual treatments (vorinostat or tadalafil) (Cuadrado-Tejedor et al, 2015) (Supplementary Figure S8a and g). This suggests a common transcriptional consequence of targeting HDAC and PDE5 simultaneously that may underlie the recovery of memory function observed in the behavior of treated animals.

However, nonsignificant results were obtained using FDR method to correct for multiple hypothesis testing. This may be because of the high degree of heterogeneity among samples as a result of the different treatment responses of each individual of the study and the low fold change of the observed expression changes. It must be taken into account that gene expression analysis was carried out after the 4-week washout period and, therefore, some of the changes that would be more evident at the end of the treatment may have faded. To reinforce changes associated with functional pathways linked to synaptic plasticity, cell-type-specific transcriptomics should be carried out by sorting neuronal and nonneuronal nuclei as recent studies have demonstrated that HDACis do not have major impact on nonneuronal cells (Benito et al, 2015). Therefore, because of lack of significant results using this conventional analysis, we used a nonparametric approach implemented in the GSEA software (Subramanian et al, 2005). This analysis revealed that CM-414 produced significant enrichment in the 'synaptic transmission' gene set in the hippocampus $(p<0.01$, Supplementary Table S3 and Supplementary Figure S8a), consistent with results shown in Figure 4e. We complemented this analysis by using Ingenuity Pathways Analysis in order to gain information about the biological function of these upregulated genes. 'CREB Signaling in Neurons' was included among the top-ranked canonical pathways $(p<0.05$, Supplementary Figure S8g), and the top ranked biological functions were 'Nervous system Development and Function' and 'Behavior' (eg, cognition, spatial learning, and recognition memory: $p<0.01$; Supplementary Figure S8h). These data demonstrate that molecular changes induced by CM-414, triggered by an epigenetic mode of action (histone acetylation) and CREB phosphorylation, were maintained after the washout period and that they may underlie the recovery of memory function observed in the treated animals.

\section{DISCUSSION}

The lack of effective treatments for $\mathrm{AD}$ along with the increase in life expectancy and the higher incidence of dementia worldwide make the development of new potential therapeutic drugs ever more urgent. Here we have identified a new first-in-class small-molecule with potential therapeutic utility in AD, CM-414, a moderate HDAC class I inhibitor and potent HDAC6 and PDE5 inhibitor. CM-414 produces a beneficial synergistic effect in $\mathrm{AD}$ mice, preventing the disruption in synaptic plasticity and reversing cognitive impairment. In addition, it provokes a significant reduction in amyloid and tau pathology, a reversion of the reduced dendritic spine density, and induces memory-related genes, all of which may underlie the enhanced memory observed in 


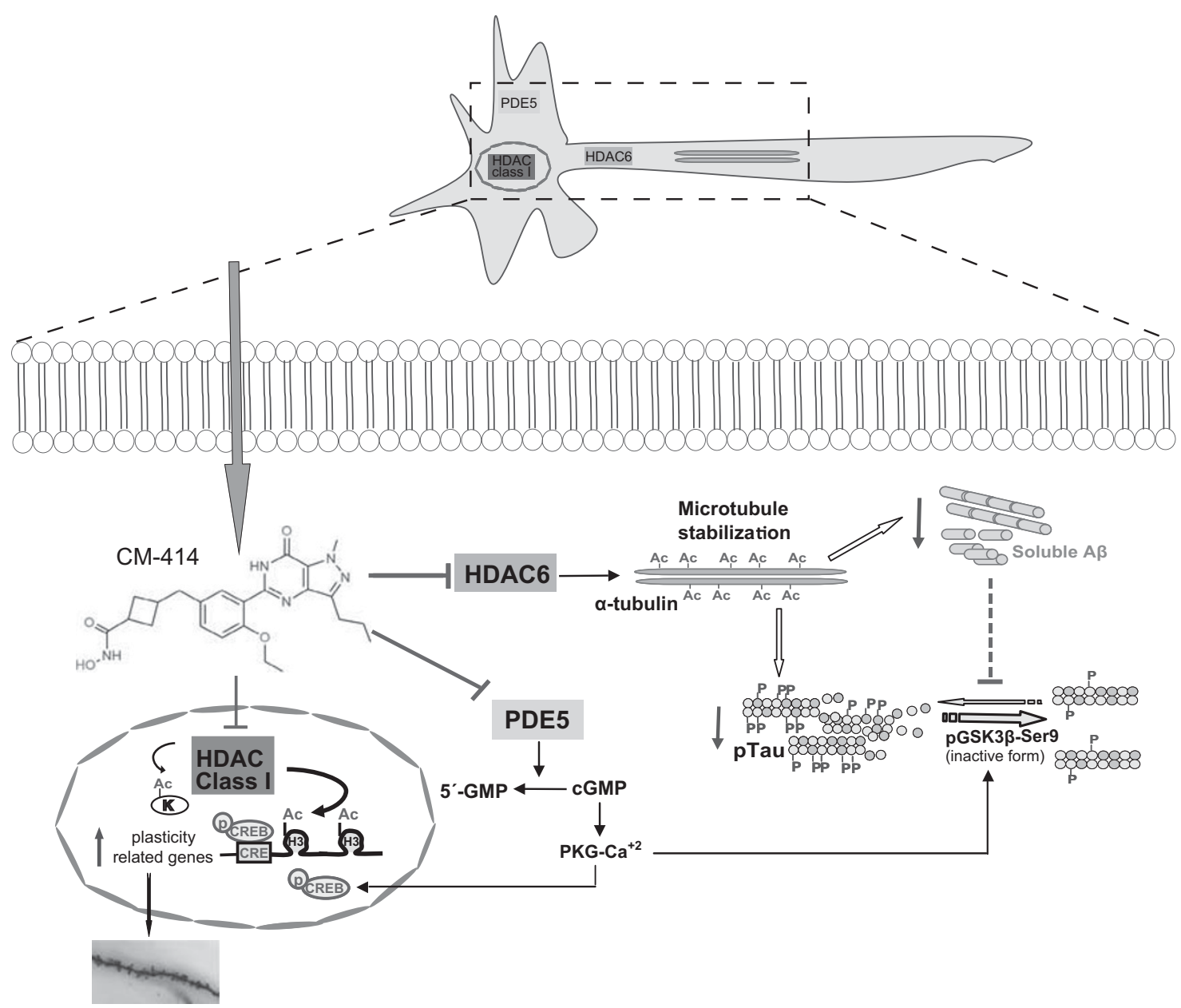

Figure 5 Proposed mechanism of action involved in the restoration of pathological signs by CM-4I4. The cartoon represents a speculative model indicative of a possible mode of action based on results and bibliography. Ac, acetyl; HDAC, histone deacetylase; PDE, phosphodiesterase; PKG, protein kinase G; K, lysine.

the treated animals. The therapeutic benefit obtained with this dual inhibitor confirmed the feasibility of discovering new multitarget compounds that can interact with multiple pathways affected in the disease as promising therapeutic tools (Cuadrado-Tejedor et al, 2015).

The complexity and multifactorial nature of $\mathrm{AD}$ suggests that multiple targets are likely to be more appropriate than individual ones when considering new therapies. The design of CM-414 is based on the inhibition of different processes that participate in distinct aspects of AD. By inhibiting PDE5, CM-414 can restore memory through the activation of the cGMP/CREB pathway that plays an important role in synaptic plasticity (Lu and Hawkins, 2002; Lu et al, 1999). Furthermore, the inhibition of PDE5 might diminish tau phosphorylation by favoring the inactive form of GSK3 $\beta$ (GSK3/-Ser9) (Cuadrado-Tejedor et al, 2011b; GarciaBarroso et al, 2013). On the other hand, through the inhibition of HDAC class I in conjunction with CREB activation, CM-414 may also facilitate the transcription of more specific memory-related genes, thereby reducing the indiscriminate transcription provoked by other HDAC class I inhibitors. In fact, the induction of genes implicated in synaptic plasticity, the formation of new dendritic spines, and the increase in pCamKII observed in mice treated with
CM-414 may at least partially underlie the restoration of memory in these transgenic mice. Finally, the inhibition of HDAC6 may facilitate the degradation of misfolded proteins, such as A $\beta$ and pTau (Sung et al, 2012; Yu et al, 2013; Zhang et al, 2014). Although different studies have demonstrated that HDACi or PDE5i improved cognitive deficits in animal models of $\mathrm{AD}$, their role on amyloid pathology is controversial (Benito et al, 2015; Cuadrado-Tejedor et al, 2011b; Garcia-Barroso et al, 2013; Puzzo et al, 2009; Qing et al, 2008; Ricobaraza et al, 2009; Rumbaugh et al, 2015; Zhang and Schluesener, 2013). These differences may be because of the selectivity and potency of each compound and the different animal models and treatments employed. How the different modes of action may lead CM-414 to reverse the pathological changes associated with $\mathrm{AD}$ is summarized in Figure 5, showing that reduction of amyloid and tau pathology and memory restoration by CM-414 is likely to involve multiple cellular processes. Nonetheless, more experiments are needed to elucidate the role of each target (HDACs and PDE5) in the global effect observed at the end of the treatment.

In the past decade, HDACis have been considered for their therapeutic potential to combat neurodegenerative disorders (Fischer et al, 2007; Kilgore et al, 2010; Reichenberg et al, 
2009). For instance, although its therapeutic effect may be attributed to its other multiple targets, the moderate HDACi, valproic acid, has already been approved by the FDA for CNS disorders (Chiu et al, 2013). In addition, it is proposed to start a study to treat $\mathrm{AD}$ patients with vorinostat (Benito et al, 2015), the first HDACi approved for cancer (Mann et al, 2007). However, besides the toxicity associated with strong inhibition of HDAC class I isoforms (Robers et al, 2015), a single-target drug may only produce limited benefits in complex diseases like $\mathrm{AD}$ and, indeed, network models suggest that the partial and simultaneous inhibition of different targets is likely to produce more efficient effects than the use of specific and high-affinity inhibitors (Lehar et al, 2009; Zheng et al, 2014). Interestingly, we had empirically validated the beneficial synergistic effect of concomitant HDAC and PDE5 inhibition in AD mice using reference compounds (vorinostat and tadalafil) (Cuadrado-Tejedor et al, 2015). Here, we achieved this dual inhibition of HDAC (class I and IIb) and PDE5 with a single molecule (CM-414) that produced a similar therapeutic and mechanistic effect in AD models. Thus, CM-414 represents an advanced and interesting starting point to launch a drug discovery program aimed at identifying preclinical candidates with optimal efficacy and safety profiles. Such target compounds would have a profile of moderate HDAC class I inhibition, potent HDAC6 and PDE5 inhibition, optimal passage across the $\mathrm{BBB}$, a short residence time, and a reduced half-life. In this way, the candidate drugs identified should have minimal toxicity as this is often associated with strong inhibition of HDAC class I isoforms (Robers et al, 2015) (eg, the FDA-approved potent pan-HDAC inhibitors, vorinostat and panobinostat) as well as with slow dissociation kinetics (Lauffer et al, 2013). The synergistic effect should lead to achieve a degree of histone 3 acetylation that is not possible with HDAC6-selective inhibitors (eg, Ricolinostat) and, on the other hand, these new molecules will also achieve a degree of tubulin acetylation that has been impossible to obtain with the FDA-approved class I inhibitor, valproic acid (Gurvich et al, 2004). Moreover, the compounds proposed will have better brain permeability than the FDA-approved HDAC (Kazantsev and Thompson, 2008) and PDE5 inhibitors (eg, Sildenafil and Tadalafil, with a $\log B \mathrm{~B}<0)($ Garcia-Barroso et al, 2013; Gomez-Vallejo et al, 2016).

In summary, the activity of the novel first-in-class CM-414 demonstrated here validates this approach as a potential new symptomatic and disease-modifying strategy to treat $\mathrm{AD}$ (Cuadrado-Tejedor et al, 2015). This compound represents an adequate starting point to launch an $\mathrm{AD}$ drug discovery program aimed at identifying optimized molecules with the target profile described herein. The proposed systems therapeutics approach defined here may open the way to a new drug discovery strategy for chronic treatment of $\mathrm{AD}$, with potential clinical benefits for patients with $\mathrm{AD}$ and other complex diseases. CM-414 can also be used as a chemical probe to elucidate additional molecular mechanisms underlying the AD phenotype and how they may be restored through this new multi-target strategy.

\section{FUNDING AND DISCLOSURE}

Mar Cuadrado-Tejedor, Obdulia Rabal, Rafael Franco, Ana Garcia-Osta and Julen Oyarzabal are inventors of the reported patent WO 2014/131855 A1 claiming this chemical series. Applicant is Fundación para la Investigación Médica Aplicada (FIMA). The rest of authors declare no conflict of interest. This work was supported by grants from FIMA (Spain), the FIS project (11/02861 and 14/01244) to AG-O, a Torres Quevedo grant (from MINECO PTQ-12-05641) to AU, an Asociación de Amigos of University of Navarra grant to MP-G, and MINECO (Ramón y Cajal Program, RYC2012-12014; and BFU2013-47265R) to GP.

\section{ACKNOWLEDGMENTS}

We thank Maria Espelosin and Susana Ursua for their work in the animal facility and cell culture.

\section{REFERENCES}

Bayer KU, Schulman H (2001). Regulation of signal transduction by protein targeting: the case for CaMKII. Biochem Biophys Res Commun 289: 917-923.

Benito E, Urbanke H, Ramachandran B, Barth J, Halder R, Awasthi A et al (2015). HDAC inhibitor-dependent transcriptome and memory reinstatement in cognitive decline models. $J$ Clin Invest 125: 3572-3584.

Bliss TV, Collingridge GL (1993). A synaptic model of memory: long-term potentiation in the hippocampus. Nature 361: 31-39.

Borchelt DR, Thinakaran G, Eckman CB, Lee MK, Davenport F, Ratovitsky $\mathrm{T}$ et al (1996). Familial Alzheimer's disease-linked presenilin 1 variants elevate Abeta1-42/1-40 ratio in vitro and in vivo. Neuron 17: 1005-1013.

Chiu CT, Wang Z, Hunsberger JG, Chuang DM (2013). Therapeutic potential of mood stabilizers lithium and valproic acid: beyond bipolar disorder. Pharmacol Rev 65: 105-142.

Cisse M, Halabisky B, Harris J, Devidze N, Dubal DB, Sun B et al (2011). Reversing EphB2 depletion rescues cognitive functions in Alzheimer model. Nature 469: 47-52.

Cook C, Gendron TF, Scheffel K, Carlomagno Y, Dunmore J, DeTure $\mathrm{M}$ et al (2012). Loss of HDAC6, a novel CHIP substrate, alleviates abnormal tau accumulation. Hum Mol Genet 21: 2936-2945.

Copeland RA, Basavapathruni A, Moyer M, Scott MP (2011). Impact of enzyme concentration and residence time on apparent activity recovery in jump dilution analysis. Anal Biochem 416: 206-210.

Cuadrado Tejedor M, Garcia Osta AM, Oyarzabal Santamarina J, Rabal Gracia MO, Novel hydroxamic acid compounds as dual inhibitors of phosphodiesterases and histone deacetylases. WO 2014/131855 A1, 2014.

Cuadrado-Tejedor M, Garcia-Barroso C, Sanzhez-Arias J, Mederos S, Rabal O, Ugarte A et al (2015). Concomitant histone deacetylase and phosphodiesterase 5 inhibition synergistically prevents the disruption in synaptic plasticity and it reverses cognitive impairment in a mouse model of Alzheimer's disease. Clin Epigenetics 7: 108.

Cuadrado-Tejedor M, Garcia-Osta A, Ricobaraza A, Oyarzabal J, Franco R (2011a). Defining the mechanism of action of 4-phenylbutyrate to develop a small-molecule-based therapy for Alzheimer's disease. Curr Med Chem 18: 5545-5553.

Cuadrado-Tejedor M, Hervias I, Ricobaraza A, Puerta E, PerezRoldan JM, Garcia-Barroso C et al (2011b). Sildenafil restores cognitive function without affecting Ass burden in an Alzheimer's disease mouse model. Br J Pharmacol 164: 2029-2041. 
Cummings JL, Morstorf T, Zhong K (2014). Alzheimer's disease drug-development pipeline: few candidates, frequent failures. Alzheimers Res Ther 6: 37.

Ding H, Dolan PJ, Johnson GV (2008). Histone deacetylase 6 interacts with the microtubule-associated protein tau. J Neurochem 106: 2119-2130.

Fischer A, Sananbenesi F, Wang X, Dobbin M, Tsai LH (2007). Recovery of learning and memory is associated with chromatin remodelling. Nature 447: 178-182.

Garcia-Barroso C, Ricobaraza A, Pascual-Lucas M, Unceta N, Rico AJ, Goicolea MA et al (2013). Tadalafil crosses the bloodbrain barrier and reverses cognitive dysfunction in a mouse model of AD. Neuropharmacology 64: 114-123.

Garcia-Osta A, Cuadrado-Tejedor M (2016). Advanced assay monitoring APP-carboxyl-terminal fragments as markers of APP processing in Alzheimer disease mouse models. Methods Mol Biol 1303: 117-123.

Garcia-Osta A, Cuadrado-Tejedor M, Garcia-Barroso C, Oyarzabal J, Franco R (2012). Phosphodiesterases as therapeutic targets for Alzheimer's disease. ACS Chem Neurosci 3: 832-844.

Gentleman VC, Dudoit S, Irizarry R, Huber W (eds). Bioinformatics and Computational Biology Solutions using $R$ and Bioconductor. Springer: New York, NY, 2006.

Giese KP, Mizuno K (2013). The roles of protein kinases in learning and memory. Learn Mem 20: 540-552.

Glaser EM, Van der Loos H (1981). Analysis of thick brain sections by obverse-reverse computer microscopy: application of a new, high clarity Golgi-Nissl stain. J Neurosci Methods 4: $117-125$.

Goguel V, Belair AL, Ayaz D, Lampin-Saint-Amaux A, Scaplehorn N, Hassan BA et al (2011). Drosophila amyloid precursor protein-like is required for long-term memory. J Neurosci 31: 1032-1037.

Gomez-Vallejo V, Ugarte A, Garcia-Barroso C, Cuadrado-Tejedor M, Szczupak B, Dopeso-Reyes IG et al (2016). Pharmacokinetic investigation of sildenafil using positron emission tomography and determination of its effect on cerebrospinal fluid cGMP levels. J Neurochem 136: 403-415.

Graff J, Rei D, Guan JS, Wang WY, Seo J, Hennig KM et al (2012). An epigenetic blockade of cognitive functions in the neurodegenerating brain. Nature 483: 222-226.

Guan JS, Haggarty SJ, Giacometti E, Dannenberg JH, Joseph N, Gao J et al (2009). HDAC2 negatively regulates memory formation and synaptic plasticity. Nature 459: 55-60.

Gurvich N, Tsygankova OM, Meinkoth JL, Klein PS (2004). Histone deacetylase is a target of valproic acid-mediated cellular differentiation. Cancer Res 64: 1079-1086.

Hsiao K, Chapman P, Nilsen S, Eckman C, Harigaya Y, Younkin S et al (1996). Correlative memory deficits, Abeta elevation, and amyloid plaques in transgenic mice. Science 274: 99-102.

Hubbert C, Guardiola A, Shao R, Kawaguchi Y, Ito A, Nixon A et al (2002). HDAC6 is a microtubule-associated deacetylase. Nature 417: 455-458.

Irizarry RA, Bolstad BM, Collin F, Cope LM, Hobbs B, Speed TP (2003). Summaries of Affymetrix GeneChip probe level data. Nucleic Acids Res 31: e15.

Kalin JH, Bergman JA (2013). Development and therapeutic implications of selective histone deacetylase 6 inhibitors. J Med Chem 56: 6297-6313.

Kazantsev AG, Thompson LM (2008). Therapeutic application of histone deacetylase inhibitors for central nervous system disorders. Nat Rev Drug Discov 7: 854-868.

Kilgore M, Miller CA, Fass DM, Hennig KM, Haggarty SJ, Sweatt JD et al (2010). Inhibitors of class 1 histone deacetylases reverse contextual memory deficits in a mouse model of Alzheimer's disease. Neuropsychopharmacology 35: 870-880.

Langley B, D'Annibale MA, Suh K, Ayoub I, Tolhurst A, Bastan B et al (2008). Pulse inhibition of histone deacetylases induces complete resistance to oxidative death in cortical neurons without toxicity and reveals a role for cytoplasmic p21(waf1/cip1) in cell cycle-independent neuroprotection. J Neurosci 28: 163-176.

Langley B, Gensert JM, Beal MF, Ratan RR (2005). Remodeling chromatin and stress resistance in the central nervous system: histone deacetylase inhibitors as novel and broadly effective neuroprotective agents. Curr Drug Targets CNS Neurol Disord 4: 41-50.

Lauffer BE, Mintzer R, Fong R, Mukund S, Tam C, Zilberleyb I et al (2013). Histone deacetylase (HDAC) inhibitor kinetic rate constants correlate with cellular histone acetylation but not transcription and cell viability. J Biol Chem 288: 26926-26943.

Lehar J, Krueger AS, Avery W, Heilbut AM, Johansen LM, Price ER et al (2009). Synergistic drug combinations tend to improve therapeutically relevant selectivity. Nat Biotechnol 27: 659-666.

Lisman J, Schulman H, Cline H (2002). The molecular basis of CaMKII function in synaptic and behavioural memory. Nat Rev Neurosci 3: 175-190.

Lu YF, Hawkins RD (2002). Ryanodine receptors contribute to cGMP-induced late-phase LTP and CREB phosphorylation in the hippocampus. J Neurophysiol 88: 1270-1278.

Lu YF, Kandel ER, Hawkins RD (1999). Nitric oxide signaling contributes to late-phase LTP and CREB phosphorylation in the hippocampus. J Neurosci 19: 10250-10261.

Lucchesi W, Mizuno K, Giese KP (2011). Novel insights into CaMKII function and regulation during memory formation. Brain Res Bull 85: 2-8.

Manallack DT, Hughes RA, Thompson PE (2005). The next generation of phosphodiesterase inhibitors: structural clues to ligand and substrate selectivity of phosphodiesterases. $J$ Med Chem 48: 3449-3462.

Mandelkow EM, Drewes G, Biernat J, Gustke N, Van Lint J, Vandenheede JR et al (1992). Glycogen synthase kinase-3 and the Alzheimer-like state of microtubule-associated protein tau. FEBS Lett 314: 315-321.

Mann BS, Johnson JR, Cohen MH, Justice R, Pazdur R (2007). FDA approval summary: vorinostat for treatment of advanced primary cutaneous T-cell lymphoma. Oncologist 12: 1247-1252.

McQuown SC, Barrett RM, Matheos DP, Post RJ, Rogge GA, Alenghat $\mathrm{T}$ et al (2011). HDAC3 is a critical negative regulator of long-term memory formation. J Neurosci 31: 764-774.

Miller TA, Witter DJ, Belvedere S (2003). Histone deacetylase inhibitors. J Med Chem 46: 5097-5116.

Puzzo D, Staniszewski A, Deng SX, Privitera L, Leznik E, Liu S et al (2009). Phosphodiesterase 5 inhibition improves synaptic function, memory, and amyloid-beta load in an Alzheimer's disease mouse model. J Neurosci 29: 8075-8086.

Puzzo D, Vitolo O, Trinchese F, Jacob JP, Palmeri A, Arancio O (2005). Amyloid-beta peptide inhibits activation of the nitric oxide/cGMP/cAMP-responsive element-binding protein pathway during hippocampal synaptic plasticity. I Neurosci 25: 6887-6897.

Qing H, He G, Ly PT, Fox CJ, Staufenbiel M, Cai F et al (2008). Valproic acid inhibits Abeta production, neuritic plaque formation, and behavioral deficits in Alzheimer's disease mouse models. J Exp Med 205: 2781-2789.

Reichenberg A, Mill J, MacCabe JH (2009). Epigenetics, genomic mutations and cognitive function. Cogn Neuropsychiatry 14: 377-390.

Ricobaraza A, Cuadrado-Tejedor M, Marco S, Perez-Otano I, Garcia-Osta A (2012). Phenylbutyrate rescues dendritic spine loss associated with memory deficits in a mouse model of Alzheimer disease. Hippocampus 22: 1040-1050.

Ricobaraza A, Cuadrado-Tejedor M, Perez-Mediavilla A, Frechilla D, Del Rio J, Garcia-Osta A (2009). Phenylbutyrate ameliorates cognitive deficit and reduces tau pathology in an Alzheimer's disease mouse model. Neuropsychopharmacology 34: 1721-1732.

Robers MB, Dart ML, Woodroofe CC, Zimprich CA, Kirkland TA, Machleidt $\mathrm{T}$ et al (2015). Target engagement and drug residence time can be observed in living cells with BRET. Nat Commun 6: 10091 . 
Rumbaugh G, Sillivan SE, Ozkan ED, Rojas CS, Hubbs CR, Aceti M et al (2015). Pharmacological selectivity within class I histone deacetylases predicts effects on synaptic function and memory rescue. Neuropsychopharmacology 40: 2307-2316.

Sheng M, Greenberg ME (1990). The regulation and function of c-fos and other immediate early genes in the nervous system. Neuron 4: 477-485.

Smolen P, Baxter DA, Byrne JH (2014). Simulations suggest pharmacological methods for rescuing long-term potentiation. $J$ Theor Biol 360: 243-250.

Smyth GK (2004). Linear models and empirical Bayes methods for assessing differential expression in microarray experiments. Stat Appl Genet Mol Biol 3: Article3.

Steinerman JR, Irizarry M, Scarmeas N, Raju S, Brandt J, Albert M et al (2008). Distinct pools of beta-amyloid in Alzheimer diseaseaffected brain: a clinicopathologic study. Arch Neurol 65: 906-912.

Subramanian A, Tamayo P, Mootha VK, Mukherjee S, Ebert BL, Gillette MA et al (2005). Gene set enrichment analysis: a knowledge-based approach for interpreting genome-wide expression profiles. Proc Natl Acad Sci USA 102: 15545-15550.

Sung YM, Lee T, Yoon H, Dibattista AM, Song JM, Sohn Y et al (2012). Mercaptoacetamide-based class II HDAC inhibitor lowers Abeta levels and improves learning and memory in a mouse model of Alzheimer's disease. Exp Neurol 239C: 192-201.

Tzingounis AV, Nicoll RA (2006). Arc/Arg3.1: linking gene expression to synaptic plasticity and memory. Neuron 52: 403-407.

Ugarte A, Gil-Bea F, Garcia-Barroso C, Cedazo-Minguez A, Ramirez MJ, Franco R et al (2015). Decreased levels of cGMP in CSF are associated with cognitive decline and amyloid pathology in Alzheimer's disease. Neuropathol Appl Neurobiol 41: 471-482.

Vaillant AR, Zanassi P, Walsh GS, Aumont A, Alonso A, Miller FD (2002). Signaling mechanisms underlying reversible, activitydependent dendrite formation. Neuron 34: 985-998.

Weyer SW, Klevanski M, Delekate A, Voikar V, Aydin D, Hick M et al (2011). APP and APLP2 are essential at PNS and CNS synapses for transmission, spatial learning and LTP. EMBO J 30: 2266-2280.

Yu CW, Chang PT, Hsin LW, Chern JW (2013). Quinazolin-4-one derivatives as selective histone deacetylase-6 inhibitors for the treatment of Alzheimer's disease. J Med Chem 56: 6775-6791.

Zhang KY, Card GL, Suzuki Y, Artis DR, Fong D, Gillette S et al (2004). A glutamine switch mechanism for nucleotide selectivity by phosphodiesterases. Mol Cell 15: 279-286.

Zhang L, Liu C, Wu J, Tao JJ, Sui XL, Yao ZG et al (2014). Tubastatin A/ACY-1215 improves cognition in Alzheimer's disease transgenic mice. J Alzheimers Dis 41: 1193-1205.

Zhang ZY, Schluesener HJ (2013). Oral administration of histone deacetylase inhibitor MS-275 ameliorates neuroinflammation and cerebral amyloidosis and improves behavior in a mouse model. J Neuropathol Exp Neurol 72: 178-185.

Zheng H, Fridkin M, Youdim M (2014). From single target to multitarget/network therapeutics in Alzheimer's therapy. Pharmaceuticals (Basel) 7: 113-135.

Zheng H, Fridkin M, Youdim M (2015). New approaches to treating Alzheimer's disease. Perspect Medicin Chem 7: 1-8.

Supplementary Information accompanies the paper on the Neuropsychopharmacology website (http://www.nature.com/npp) 